\title{
Activity-Dependent Degradation of Synaptic Vesicle Proteins Requires Rab35 and the ESCRT Pathway
}

\author{
Patricia Sheehan, ${ }^{1}$ Mei Zhu, ${ }^{1}$ Anne Beskow, ${ }^{1}{ }^{\circledR}$ Cyndel Vollmer, ${ }^{1}$ and $\mathbb{C}^{-C l a r i s s a}$ L. Waites ${ }^{1,2}$ \\ ${ }^{1}$ Department of Pathology and Cell Biology and ${ }^{2}$ Department of Neuroscience, Columbia University Medical Center, New York, New York 10032
}

Synaptic vesicle (SV) pools must maintain a functional repertoire of proteins to efficiently release neurotransmitter. The accumulation of old or damaged proteins on SV membranes is linked to synaptic dysfunction and neurodegeneration. However, despite the importance of SV protein turnover for neuronal health, the molecular mechanisms underlying this process are largely unknown. Here, we have used dissociated rat hippocampal neurons to investigate the pathway for SV protein degradation. We find that neuronal activity drives the degradation of a subset of SV proteins and that the endosomal sorting complex required for transport (ESCRT) machinery and SVassociated GTPase Rab35 are key elements of this use-dependent degradative pathway. Specifically, neuronal activity induces Rab35 activation and binding to the ESCRT-0 protein Hrs, which we have identified as a novel Rab35 effector. These actions recruit the downstream ESCRT machinery to SV pools, thereby initiating SV protein degradation via the ESCRT pathway. Our findings show that the Rab35/ESCRT pathway facilitates the activity-dependent removal of specific proteins from SV pools, thereby maintaining presynaptic protein homeostasis.

Key words: ESCRT; Hrs; Rab35; SV2; synaptic vesicle; VAMP2

\section{Significance Statement}

Synaptic transmission is mediated by the release of chemical neurotransmitters from synaptic vesicles (SVs). This tightly regulated process requires a functional pool of SVs, necessitating cellular mechanisms for removing old or damaged proteins that could impair SV cycling. Here, we show that a subset of SV proteins is degraded in an activity-dependent manner and that key steps in this degradative pathway are the activation of the small GTPase Rab35 and the subsequent recruitment of the endosomal sorting complex required for transport (ESCRT) machinery to SV pools. Further, we demonstrate that ESCRT-0 component Hrs is an effector of Rab35, thus providing novel mechanistic insight into the coupling of neuronal activity with SV protein degradation and the maintenance of functional SV pools.

\section{Introduction}

In order for neurons to maintain efficient neurotransmission, synaptic vesicles (SVs) must undergo repeated cycles of exocytosis, endocytosis, and vesicle reformation. These processes depend

\footnotetext{
Received March 4, 2016; revised June 23, 2016; accepted June 29, 2016.

Author contributions: P.S. and C.L.W. designed research; P.S., M.Z., A.B., C.V., and C.L.W. performed research; P.S., M.Z., A.B., C.V., and C.L.W. analyzed data; P.S. and C.L.W. wrote the paper.

This work was supported by Columbia University startup funds (Departments of Pathology \& Cell Biology and Neuroscience), National Institutes of Health Grant NS080967 to C.W., and a Swedish Research Council postdoctoral fellowship to A.B. We thank Dr. Peter McPherson (Montreal Neurological Institute, McGill University, Montreal, Quebec, Canada) for the generous gift of Rab35 antibody, Dr. Craig Garner (Charité-Universitätsmedizin Berlin) for providing multiple DNA constructs (pZOff 2.0, FUGWm, FUGWH1, VSVg, $\triangle$ P, mCh-CHMP2B, EGFP-Rab3), Dr. Gil Di Paolo (Columbia University and Denali Therapeutics) for the EGFP-Rab5 construct and critical reading of the manuscript, Dr. Ulrich Hengst (Columbia University) for critical reading of the manuscript, and members of the C.L.W. laboratory for scientific input.

The authors declare no competing financial interests.

Correspondence should be addressed to Dr. Clarissa L. Waites, Departments of Pathology \& Cell Biology and Neuroscience, 650 West 168th Street, New York, NY 10032. E-mail: cw2622@cumc.columbia.edu.

DOI:10.1523/JNEUROSCI.0725-16.2016

Copyright $\odot 2016$ the authors $\quad 0270-6474 / 16 / 368668-19 \$ 15.00 / 0$
}

upon SV-associated proteins whose proper conformation and function are of paramount importance to neuronal health (Bezprozvanny and Hiesinger, 2013; Wang et al., 2013). Indeed, the buildup of damaged or misfolded SV proteins can lead to synaptic dysfunction and neurodegeneration (Garden and La Spada, 2008; Scott et al., 2010; Uytterhoeven et al., 2011). However, although the molecules that mediate SV exocytosis and endocytosis are well characterized, little is known about the pathways responsible for SV protein removal/degradation.

In addition to its role in cellular homeostasis, protein degradation is also essential for synaptic plasticity and synapse formation/elimination, processes tightly linked to neuronal activity (Alvarez-Castelao and Schuman, 2015). Although the ability of neuronal activity to regulate postsynaptic protein degradation has been demonstrated (Ehlers, 2003; Schwarz et al., 2010; Lussier et al., 2011; Scudder et al., 2014), few studies have examined the relationship between activity and presynaptic protein turnover. It has been reported that silencing neurons leads to the accumulation of presynaptic proteins (Lazarevic et al., 2011), 
Table 1. List of DNA constructs used in this study

\begin{tabular}{|c|c|c|c|c|}
\hline Name of protein & Species & Accession no. & Source & Vector and cloning information \\
\hline Rab35 & Rat & NM_001013046.1 & Genewiz, gene synthesis & $\begin{array}{l}\text { Subcloned into pEGFP/mCh-C2 and pKH3 vectors at EcoRI site, } \\
\text { moved into FUGWm with Mfel/Nhel and EcoRI/Xbal } \\
\text { (FUGWm), PCR into pGEX-4T2 at Sall/Notl sites }\end{array}$ \\
\hline Rab3 & Human & & Gift from C. Garner & $\begin{array}{l}\text { Received in pEGFP vector subcloned mCh at Agel/BsrGl sites, } \\
\text { moved into FUGWm using Mfel/Nhel and EcoRI/Xbal } \\
\text { (FUGWm) }\end{array}$ \\
\hline Rab5 & Human & & Gift from G. DiPaolo & $\begin{array}{l}\text { Received in pEGFP, subcloned mCh at Agel/BsrGl sites, moved } \\
\text { into FUGW using Mfel/Nhel, PCR into pKH3 at BamHI/Clal } \\
\text { sites }\end{array}$ \\
\hline Rab10 & Rat & NM_017359.2 & Genewiz, gene synthesis & $\begin{array}{l}\text { Subcloned into pEGFP/mCh-C2 and pKH3 vector at EcoRl site, } \\
\text { moved into FUGWm with Mfel/Nhel and EcoRI/Xbal } \\
\text { (FUGWm) }\end{array}$ \\
\hline Rab14 & Rat & NM_053589.1 & Genewiz, gene synthesis & $\begin{array}{l}\text { Subcloned into pEGFP/mCh-C2 and pKH3 vector at EcoRl site, } \\
\text { moved into FUGWm with Mfel/Nhel and EcoRI/Xbal } \\
\text { (FUGWm) }\end{array}$ \\
\hline Rab21 & Rat & NM_001004238.1 & Genewiz, gene synthesis & Subcloned into pKH3 vector at EcoRI site \\
\hline Hrs & Human & & Addgene \#29685 & $\begin{array}{l}\text { Received in RFP vector, moved into FUGWm using Mfel/Nhel, } \\
\text { PCR into pCS2-FLAG at Xhol/Xbal sites }\end{array}$ \\
\hline TSG101 & Human & & Addgene \#38318 & Received in $\mathrm{mCh}$ vector, used as is \\
\hline STAM & Human & & Addgene \#21499 & Subcloned into pmCh N1 at Xhol/Hindlll sites \\
\hline CHMP2B & Human & & Gift from C. Garner & Received in pmCh-C2 vector, used as is \\
\hline Connecdenn1/DENND1A & Rat & NM_001191747.1 & Genewiz, gene synthesis & Subcloned into pEGFP-C1 at EcoRI site \\
\hline
\end{tabular}

suggesting that their turnover is slowed in the absence of activity; however, the direct effects of neuronal activity on SV protein degradation have not been investigated.

Furthermore, the cellular pathways responsible for SV protein turnover are poorly understood. One candidate pathway is the endosomal sorting complex required for transport (ESCRT) system, which catalyzes the formation of multivesicular bodies (MVBs) to deliver proteins to lysosomes. Indeed, MVBs can be detected in presynaptic boutons by electron microscopy (Ceccarelli et al., 1973; LaVail and LaVail, 1975; Teichberg et al., 1975) and often appear following neuronal stimulation (Teichberg et al., 1975), suggesting that their formation may be activity-dependent.

Another class of molecules that regulate protein trafficking and turnover are Rab GTPases. These small GTPases act as molecular switches that cycle between active (GTP-bound) and inactive (GDP-bound) states. GTP-bound Rabs in turn recruit effectors that catalyze downstream trafficking events (Stenmark, 2009). Among the $>60$ Rabs in mammalian brain, at least 30 are reported to associate with SV pools (Takamori et al., 2006; Pavlos and Jahn, 2011), but only a few of these have well-established roles in the SV cycle (Schlüter et al., 1999, 2004; Mahoney et al., 2006; Yu et al., 2008; Pavlos et al., 2010; Pavlos and Jahn, 2011). Several other Rabs are implicated in the endosomal sorting of SV proteins (Wucherpfennig et al., 2003; Rizzoli et al., 2006; Takamori et al., 2006; Hoopmann et al., 2010; Uytterhoeven et al., 2011). For example, recent studies have demonstrated that loss of function of Skywalker/TBC1D24, a Rab GTPase-activating protein (GAP), leads to Rab35 overactivation and the excessive endosomal sorting and replenishment of SV proteins in Drosophila. The ESCRT system and homotypic fusion and vacuole proteinsorting complex were identified through genetic interactions as downstream components of this pathway (Uytterhoeven et al., 2011; Fernandes et al., 2014). However, other SVassociated Rabs (i.e., 5, 11, 26) are implicated in macroautophagy (Ao et al., 2014; Binotti et al., 2015), another lysosomal degradative pathway that may also be important for $\mathrm{SV}$ protein turnover. Indeed, macroautophagy has been shown to mediate the degradation of SVs under certain conditions (Hernandez et al., 2012). Thus, the pathway(s) for SV protein degradation, and the roles of SV-associated Rabs in regulating this process, remain unresolved.

Here, we demonstrate that neuronal activity is a key regulator of degradation for a subset of SV proteins, and we identify the ESCRT system and Rab35 as essential components of this usedependent degradative pathway. Further, we provide important mechanistic insight into how activity drives protein degradation, by stimulating the activation of Rab35, the binding of Rab35 to ESCRT-0 component Hrs, and the recruitment of downstream ESCRT proteins to SV pools. Overall, our findings demonstrate that the Rab35/ESCRT pathway mediates the use-dependent degradation of SV membrane proteins, thus maintaining SV protein homeostasis at presynaptic terminals.

\section{Materials and Methods}

Cultured rat neurons. Hippocampal neurons were prepared from E18 Sprague Dawley rat embryos of either sex using a modified Banker culture protocol (Banker and Goslin, 1998; Waites et al., 2009). Briefly, neurons were dissociated in TrypLE Express (Fisher/Invitrogen) for 20 min, washed with Hanks Balanced Salt Solution (Sigma), and plated in Neurobasal medium with B27 supplement and Glutamax (all Invitrogen) at a density of 250,000 neurons per well ( 12 well plates) or coverslip $(22 \times 22 \mathrm{~mm}$ square $)$.

Constructs, shRNAs. Sources of the constructs used are listed in Table 1. For shRNAs, target sequences for rat Rab35, Hrs, and TSG101 were modified from published work or designed using siDirect (http://sidirect2.rnai.jp/). Target sequences are as follows: Rab35: 5'-GGGCAGATGGGGATCCA GC-3' (nucleotides 418-436) (Allaire et al., 2010); Hrs: 5' -GAACTACTGG GAGAAGAAA-3' (nucleotides 996-1014); and TSG101:5'-GGATGAAGG AGGAAATGGA-3' (nucleotides 725-743). shRNAs were subcloned into pZOff 2.0 and subsequently into the modified FUGW H1 vector as described previously (Leal-Ortiz et al., 2008). To evaluate shRNA knockdown efficiency, neurons were transduced with lentivirus on 3-7 DIV, collected on 12-16 DIV, and processed for immunoblotting as described below. Protein intensity was measured and compared with that in neurons expressing a scrambled hairpin (scRNA). Transduction was timed to achieve the highest knockdown efficacy without noticeable toxicity (assessed by bright-field microscopy). To create shRab35-resistant Rab35, the following mutations 
(shown in italics) were made to rat Rab35 5'-GGCCAAATGGGCATT CAAC-3' (nucleotides 418-436). Neurons were transduced with either scRNA or shRab35 on 3 DIV then on 9 DIV with sh-resistant Rab35.

Pharmacological treatments. Pharmacological agents were used in the following concentrations and time courses: cycloheximide (Calbiochem, $0.2 \mu \mathrm{g} / \mu \mathrm{l}, 24 \mathrm{~h}$ ), bicuculline (Sigma, $40 \mu \mathrm{M}, 12-24 \mathrm{~h}$ ), 4-aminopyridine (Tocris Bioscience, $50 \mu \mathrm{M}, 12-24 \mathrm{~h}$ ), AP5 (Tocris Bioscience, $50 \mu \mathrm{M}$, $24 \mathrm{~h}$ ), CNQX (Tocris Bioscience, $10 \mu \mathrm{M}, 24 \mathrm{~h}$ ), TTX (Tocris Bioscience, $0.5 \mu \mathrm{M}, 24 \mathrm{~h}$ ), GDP (Sigma, $5 \mathrm{~mm}$ ), GTP $\gamma \mathrm{s}$ (Sigma, $5 \mathrm{~mm}$ ), and PR-619 (LifeSensors, $50 \mu \mathrm{M}, 6 \mathrm{~h}$ ).

Evaluation of neuronal health. The 14 DIV hippocampal neurons on coverslips were treated with $0.2 \mu \mathrm{g} / \mu \mathrm{l}$ cycloheximide for $24-36 \mathrm{~h}$, fixed in Lorene's Fix, and processed for immunostaining against Tau (polyclonal; Synaptic Systems) and MAP2 (monoclonal; Sigma), mounted with DAPI Vectashield (Vector Laboratories), and images acquired as described (see Immunofluorescence microscopy). The following features were scored per field of view: condensed nuclei (DAPI staining in MAP2 positive neurons), enlarged cell bodies (DAPI/MAP2 area), blebbing dendrites (based on MAP2 staining), and axonal beading (punctate Tau staining). In control conditions, $<15 \%$ of neurons exhibited one or more of these features.

Electrophysiology. Changes in neuronal activity in the presence of bicuculline/4-aminopyridine or CNQX/APV/TTX were measured using whole-cell voltage-clamp electrophysiology. Dissociated hippocampal neurons were recorded on DIV 15 at room temperature using a Multiclamp 700B amplifier (Molecular Devices) and a 1550A Digidata digitizer (Molecular Devices) interfaced to a computer equipped with Clampex 10 software (Molecular Devices). Neurons were continuously perfused with extracellular solution $(140 \mathrm{~mm} \mathrm{NaCl}, 2.4 \mathrm{~mm} \mathrm{KCl,} 10 \mathrm{~mm}$ HEPES, $10 \mathrm{~mm}$ glucose, $4 \mathrm{~mm} \mathrm{CaCl}_{2}, 4 \mathrm{~mm} \mathrm{MgCl}_{2}$, pH 7.35, $300 \mathrm{mOsm}$ ) via a gravity-based perfusion system. Patch pipettes pulled from borosilicate glass (World Precision Instruments) had resistances of 4-5 $\mathrm{m} \Omega$ when filled with intracellular solution $(135 \mathrm{~mm}$ K-gluconate, $10 \mathrm{~mm}$ HEPES, 1 mM EGTA, $4.6 \mathrm{~mm} \mathrm{MgCl}_{2}$, 4 mм Na-ATP, $15 \mathrm{~mm}$ creatine phosphate, $\mathrm{pH} 7.35,320 \mathrm{mOsm})$. The series resistance was $<15 \mathrm{M} \Omega$ and experienced minimal change $(<15 \%)$ from the start of the recording to the end of the recording. The membrane potential was clamped at -70 $\mathrm{mV}$. Following baseline activity recordings for $4 \mathrm{~min}$, either $40 \mu \mathrm{M}$ bicuculline/50 $\mu \mathrm{M}$ 4-aminopyridine or $10 \mu \mathrm{M}$ CNQX/50 $\mu \mathrm{M}$ APV/0.5 $\mu \mathrm{M}$ TTX, was perfused onto the neurons and recording continued for a further 6 min. Traces were analyzed using MiniAnalysis software. Activity was measured as the frequency of spontaneous EPSCs during the first 4 min (baseline) and the last 4 min (with drug) of the trace.

Lentivirus production, transduction, and DNA transfection. Lentivirus was produced as previously described (Lois et al., 2002; Leal-Ortiz et al., 2008), except that Calfectin (SignaGen Laboratories) was used for transfection of HEK293T cells. HEK medium was replaced with Neurobasal medium 18-24 $\mathrm{h}$ after transfection, and this medium (viral supernatant) was harvested $24 \mathrm{~h}$ later. Neurons were transduced with 50-200 $\mu \mathrm{llen-}$ tiviral supernatant/well (6 or 12 well plates) between 3 and 10 DIV depending on the experiment (see Results), and processed for immunoblotting or immunocytochemistry between 14 and 15 DIV. For biochemical experiments, high viral titer producing $>80 \%$ infectivity was ensured by transducing test wells of neurons with varying amounts of virus and calculating of the number of infected cells divided by the number of DAPI-positive nuclei (DAPI VectaShield, Vector Laboratories) per field of view using fluorescence microscopy.

Neurons were transfected using Lipofectamine 2000 (Invitrogen) on 7-10 DIV. For each $22 \times 22 \mathrm{~mm}$ coverslip, $2.5 \mu \mathrm{l}$ Lipofectamine was incubated with $62.5 \mu \mathrm{l}$ Neurobasal for $5 \mathrm{~min}$, combined with 1-2.5 $\mu \mathrm{g}$ DNA diluted in $62.5 \mu \mathrm{l}$ Neurobasal for $20 \mathrm{~min}$, then added to neurons for $45 \mathrm{~min}$ at $37^{\circ} \mathrm{C}$. Neurons were transfected in Neurobasal medium containing $50 \mu \mathrm{M}$ AP5 and $10 \mu \mathrm{M}$ CNQX, and returned to their original dishes and medium following transfection. Neurons were fixed for immunofluorescence microscopy on 12-16 DIV.

Immunofluorescence microscopy. Primary antibodies are listed in Table 2. Alexa-488- or Alexa-647-conjugated secondary antibodies (Invitrogen) were used at 1:800 or 1:400, respectively. Neurons were immunostained as described previously (Leal-Ortiz et al., 2008). Briefly, cov-
Table 2. Antibodies used in this study

\begin{tabular}{llll}
\hline Antibody & Source & Species & Catalog no. \\
\hline VAMP2 & Synaptic Systems & Rabbit & 104202 \\
VAMP2 & Synaptic Systems & Mouse & 104211 \\
SV2 & Developmental Studies Hybridoma Bank & Mouse & \\
Tubulin & Abcam & Rabbit & ab4074 \\
Tubulin & Sigma & Mouse & t9026 \\
mCherry & Biovision & Rabbit & 5993 \\
Hrs & Santa Cruz Biotechnology & Rabbit & m-79 sc30221 \\
Rab35 & Gift from Peter McPherson & Rabbit & \\
Synaptotagmin1 & Synaptic Systems & Rabbit & 105012 \\
Snap-25 & Synaptic Systems & Mouse & 111011 \\
Rim1 $\alpha$ & Synaptic Systems & Rabbit & 140003 \\
Munc-13 & Synaptic Systems & Rabbit & 126102 \\
Synaptophysin & Santa Cruz Biotechnology & Rabbit & h-93 sc 9116 \\
HA & Santa Cruz Biotechnology & Rabbit & y-11 sc805 \\
HA & Santa Cruz Biotechnology & Mouse & f-7 sc7392 \\
Flag & Sigma & Mouse & clone m2 f3165 \\
TSG101 & Santa Cruz Biotechnology & Mouse & c-2 sc7964 \\
Tau & Santa Cruz Biotechnology & Rabbit & V-20 sc1996 \\
MAP2 & Sigma & Mouse & ap-20 m1406 \\
Synapsin 1 & Synaptic Systems & Mouse & 106001 \\
Rab3 & Synaptic Systems & Mouse & 107111 \\
Rab5 & Santa Cruz Biotechnology & Mouse & D-11 sc-46692 \\
Rab10 & Santa Cruz Biotechnology & Goat & C-18 sc-6564 \\
Rab14 & Santa Cruz Biotechnology & Rabbit & H-55 sc-98610 \\
Active Rab35 & NewEast Biosciences & Mouse & 26922 \\
Rab35 & Proteintech & Rabbit & $11329-2-$ AP \\
GST & Abcam & Rabbit & ab9085 \\
Homer 1 & Synaptic Systems & Rabbit & 160003 \\
\hline & & & \\
\hline
\end{tabular}

erslips were fixed with Lorene's Fix (60 mM PIPES, 25 mм HEPES, $10 \mathrm{~mm}$ EGTA, $2 \mathrm{~mm} \mathrm{MgCl}_{2}, 0.12 \mathrm{~m}$ sucrose, 4\% formaldehyde) for $15 \mathrm{~min}$, primary and secondary antibody incubations were performed in blocking buffer ( $2 \%$ glycine, $2 \%$ BSA, $0.2 \%$ gelatin, $50 \mathrm{mM} \mathrm{NH}_{4} \mathrm{Cl}$ in $1 \times \mathrm{PBS}$ ) for $1-2 \mathrm{~h}$ at room temperature or overnight at $4^{\circ} \mathrm{C}$, and all washes were done with PBS. Coverslips were mounted with DAPI VectaShield (Vector Laboratories) and sealed with clear nail polish. Images were acquired with a $40 \times$ objective (Neofluar, NA 1.3 ) or a $63 \times$ objective (Neofluar, NA 1.4) on an epifluorescence microscope (Axio Observer Z1, Zeiss) with Colibri LED light source, EMCCD camera (Hamamatsu) and Zen 2012 (blue edition) software. Super-resolution imaging was performed with a Zeiss LSM 800 confocal microscope equipped with Airyscan module, using a $63 \times$ objective (Plan-Apochromat, NA 1.4). Images were obtained and processed using Zen Blue 2.1 software.

SNAP labeling. SNAP-Cell Oregon Green (New England BioLabs) was diluted in Neurobasal media to a final concentration of $10 \mu \mathrm{M}$. The 13 DIV neurons were incubated for $30 \mathrm{~min}$ at $37^{\circ} \mathrm{C}$, washed 3 times with Neurobasal media, incubated for $30 \mathrm{~min}$ at $37^{\circ} \mathrm{C}$ in fresh media, washed once more, and returned to the original media (adapted from Bodor et al., 2012). At $15 \mathrm{~h}$ and $2 \mathrm{~d}$ after SNAP labeling, neurons were fixed, immunostained using anti-Flag antibody, and imaged as described above.

Image analyses. Colocalization analyses of $\mathrm{Hrs}$ and CHMP2B with VAMP2 were performed manually in ImageJ using the Time Series Analyzer V2 plugin (Balaji) to create ROIs $(8 \times 8$, oval) over Hrs or CHMP2B puncta. ROIs with VAMP2 immunostaining above a threshold value (determined empirically, typically $<5 \%$ in threshold window) were counted and expressed as a fraction of the total. Puncta intensity analyses were performed in ImageJ by creating a selection in the Rab channel and applying it to the VAMP2 channel. Mean intensity values of VAMP2 puncta (gray values) were then measured using the Analyze Particles function. The experimental condition was reported as a fraction of the control condition by dividing intensity values from three experimental images by the average of three images from the control condition. In experiments coexpressing shHrs or scrambled shRNAs with mChRab35, VAMP2 intensity was measured in OpenView (written by Noam Ziv, Technion Institute, Haifa, Israel) as described previously (Waites et 
al., 2011). Briefly, VAMP2 puncta were selected from processes expressing both EGFP and mCh-Rab protein, mean intensity values were measured, and average intensity calculated and reported as in the ImageJ analyses. Puncta per unit length (measured in arbitrary units) was calculated in ImageJ using the "freehand line" tool to trace and measure Taupositive axons containing Hrs puncta. To measure BG-Oregon Green colocalization with Flag, the ImageJ colocalization plug-in (Pierre Bourdoncle) was used. BG-Oregon Green and Flag puncta above a threshold value were determined empirically, total versus colocalized puncta counts were measured using the Analyze Particles function, and the fraction of colocalized puncta over total Flag puncta calculated. OpenView was used to measure BG-Oregon Green intensity as described above.

Coimmunoprecipitation and pull-down assays. For coimmunoprecipitation studies, HEK293T cells were transfected using Calfectin according to the manufacturer's protocol (SignaGen Laboratories). Cell lysates were collected $48 \mathrm{~h}$ after transfection in lysis buffer (50 mM Tris-Base, 150 $\mathrm{mm} \mathrm{NaCl}, 1 \%$ Triton X-100, 0.5\% deoxycholic acid) with protease inhibitor mixture (Roche) and clarified by centrifugation at high speed $(20,000 \mathrm{rcf})$. For neuronal coimmunoprecipitation and pull-down studies, neurons were transduced between 7 and 10 DIV and collected in lysis buffer on 14-15 DIV. Neuronal lysates were centrifuged at low speed (1000 rcf) to pellet nuclei. Resulting supernatant from HEK293T cells or neurons was incubated with Dynabeads (Invitrogen) coupled to antiFlag (monoclonal; Sigma), anti-mCherry (polyclonal; Biovision), anti-HA (monoclonal; Santa Cruz Biotechnology), anti-VAMP2 (monoclonal; Synaptic Systems), or anti-GTP-Rab35 (NewEast Biosciences) antibodies. For all studies, lysates were incubated at $4^{\circ} \mathrm{C}$ under constant rotation for $1-2 \mathrm{~h}$. Beads were washed 2-3 times with PBS containing $0.05 \%$ Triton (PBST) and then once with PBS. Bound proteins were eluted using sample buffer (Bio-Rad) and subject to SDS-PAGE immunoblotting as described below. For active GTP-Rab35 immunoprecipitation experiments, $2.5 \mathrm{mM} \mathrm{MgCl}_{2}$ was added to all buffers.

For coimmunoprecipitation studies assessing the nucleotide dependence of the Rab35-Hrs interaction, lysates from HEK293T cells cotransfected with Flag-Hrs and HA-Rab35 were collected and clarified as above. The resulting supernatant was divided equally and treated with either 5 $\mathrm{mm}$ GDP or $5 \mathrm{~mm}$ GTP $\gamma \mathrm{s}$. Lysates were incubated at $37^{\circ} \mathrm{C}$ with agitation for $30 \mathrm{~min}$ to facilitate nucleotide exchange. Lysates were briefly chilled on ice, treated with $60 \mathrm{mM} \mathrm{MgCl}_{2}$ to lock Rab35 in either the GDP or GTP bound state, and then subjected to immunoprecipitation with anti-Flag coated Dynabeads. Bound proteins were washed as described with wash buffer containing $2.5 \mathrm{mM} \mathrm{MgCl}_{2}$, then eluted in sample buffer.

GST pull-down. GST and GST-Rab35 protein purification and pulldown were performed as described previously (Brymora et al., 2004) with minor changes. Specifically, protein expression was induced with $0.4 \mathrm{~mm}$ IPTG overnight at $25^{\circ} \mathrm{C}$, bacterial cell pellets were resuspended in a solution containing $50 \mathrm{~mm}$ Tris, $150 \mathrm{~mm} \mathrm{NaCl}, 2.5 \mathrm{~mm} \mathrm{MgCl}_{2}$ with protease inhibitors at pH 7.4, and cells were subsequently lysed in the same buffer with $0.5 \%$ Triton X added. GST, GST-Rab35-GDP, or GST-Rab35GTP $\gamma$ s was coupled to agarose beads, then incubated with HEK293T lysate expressing Flag-Hrs for $2 \mathrm{~h}$ at $4^{\circ} \mathrm{C}$ under constant rotation. Beads were then washed 3 times in $50 \mathrm{~mm}$ Tris, $150 \mathrm{~mm} \mathrm{NaCl}$, $2.5 \mathrm{~mm} \mathrm{MgCl}_{2}$, $0.5 \%$ Triton $\mathrm{X}$ with protease inhibitors and once in the same buffer without Triton. Proteins were eluted directly in $2 \times$ SDS sample buffer (Bio-Rad) and processed for immunoblotting as described below. For all coimmunoprecipitation and pull-down assays, $1 \%-5 \%$ of lysate applied to the beads was run as "input."

Immunoblotting. For all other immunoblotting experiments, neurons were collected directly in $2 \times$ SDS sample buffer (Bio-Rad). Samples were subjected to SDS-PAGE, transferred to nitrocellulose membranes, and probed with primary antibody (Table 2 ) in $5 \%$ BSA/PBS $+0.05 \%$ Tween 20 overnight at $4^{\circ} \mathrm{C}$, followed by DyLight 680 or 800 anti-rabbit, antimouse, or anti-goat secondary antibodies (Thermo Scientific) for $1 \mathrm{~h}$. Membranes were imaged using an Odyssey Infrared Imager (model 9120, LI-COR Biosciences). Protein intensity was measured using the "Gels" function in ImageJ.

Fold change calculation. For cycloheximide-chase experiments, the normalized intensity of protein remaining after $24 \mathrm{~h}$ of treatment was reported as a fraction of the normalized intensity of that protein in lysates from the
Table 3. Fractional protein degradation in a $24 \mathrm{~h}$ period, based on neuronal activity levels ${ }^{a}$

\begin{tabular}{lcll}
\hline Protein & DMSO & APV/CNQX/TTX & Bic/4AP \\
\hline VGLUT1 & $1.04 \pm 0.08$ & NA & NA \\
Synaptophysin & $0.98 \pm 0.08$ & NA & NA \\
SV2 & $0.811 \pm 0.029$ & $0.854 \pm 0.042$ & $0.669 \pm 0.026^{*}$ \\
VAMP2 & $0.813 \pm 0.031$ & $0.840 \pm 0.047$ & $0.647 \pm 0.048^{*}$ \\
Synaptotagmin1 & $0.691 \pm 0.021$ & $0.614 \pm 0.012$ & $0.657 \pm 0.052$ \\
SNAP-25 & $0.723 \pm 0.042$ & $0.732 \pm 0.044$ & $0.628 \pm 0.076$
\end{tabular}

${ }^{a}$ The fractional amount of degradation that occurred over $24 \mathrm{~h}$ was expressed as a ratio of protein intensity with cycloheximide treatment to its intensity with DMSO control treatment. Values indicate mean \pm SEM. Student's two-tailed $t$ tests were used to calculate significance of each experimental condition versus DMSO control. NA, Not applicable.

${ }^{*} p<0.01$ (significant difference).

same condition with DMSO treatment. Protein levels were first normalized to the intensity of tubulin. Next, the fractional amount of degradation that occurred for each protein over the $24 \mathrm{~h}$ period was calculated by dividing its intensity with cycloheximide treatment to its intensity with DMSO control treatment (Table 3). These fractional amounts of degradation were further normalized to "fold change in degradation versus control" by dividing the perturbation condition (i.e., blockers, Bic/4AP, shRNA) by the control condition (i.e., DMSO, scRNA).

Statistical analyses. Graphing and statistics were performed using Prism (GraphPad). Unpaired, two-tailed $t$ tests were used to calculate $p$ values for all bar graph analyses.

\section{Results}

\section{Neuronal activity stimulates the degradation of SV} membrane proteins

We first developed an assay to monitor the degradation of SV integral membrane proteins. A previous study used the protein synthesis inhibitor cycloheximide to monitor protein degradation in neurons (Sharma et al., 2011), and we tested this approach in hippocampal neurons cultured for 14 DIV, using DMSO (vehicle control) or cycloheximide to block protein synthesis for 24 or $36 \mathrm{~h}$. We performed immunostaining against Tau (axonal protein) and MAP2 (dendritic protein), and counterstained with the nuclear label DAPI to evaluate whether this long-term cycloheximide treatment caused neuronal toxicity, reflected by enlarged cell bodies, dendritic blebbing, axonal beading, and nuclear chromatin condensation (Fig. 1A,B). We found that $36 \mathrm{~h}$ of cycloheximide treatment led to one or more of these phenotypes in $>60 \%$ of the fields of view scored, but that $24 \mathrm{~h}$ of cycloheximide did not cause any detectable changes in neuronal health versus DMSO treatment alone (Fig. $1 A, B$ ). Given this $24 \mathrm{~h}$ cycloheximide treatment window, we next assessed whether it was possible to detect SV protein degradation during this time period. Lysates from neurons treated for $24 \mathrm{~h}$ with DMSO or cycloheximide were collected and subjected to immunoblotting with antibodies against SV integral membrane proteins (VGLUT1, synaptophysin [Syp], SV2, synaptotagmin1 [Syt1], VAMP2) and the plasma membrane-associated SNARE protein SNAP-25. Resulting immunoblots were imaged using the Odyssey Imaging System (LI-COR), which acquires images in the linear range without saturation or overexposure of protein bands, enabling very accurate quantification of protein levels. For each protein, the fractional amount of degradation that occurred over $24 \mathrm{~h}$ was expressed as a ratio of its intensity with cycloheximide treatment to its intensity with DMSO control treatment (Fig. 1C,D; Table 3), and normalized to tubulin. Because tubulin is a very stable protein, its levels were nearly always unchanged over the $24 \mathrm{~h}$ time course. However, we found that the levels of SV2, Syt1, VAMP2, and SNAP-25 all decreased by 20\%-35\% within this time frame, whereas VGLUT1 and Syp levels were not significantly altered (Fig. 1C,D; Table 3). These findings indicate that 
A

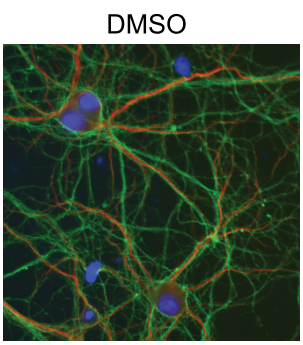

MAP2/Tau/DAPI
$24 \mathrm{hrs} \operatorname{chx}$

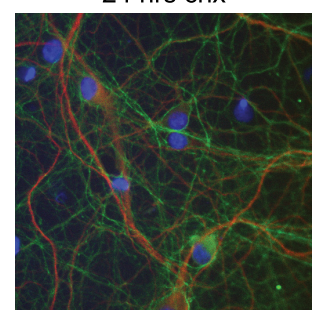

C

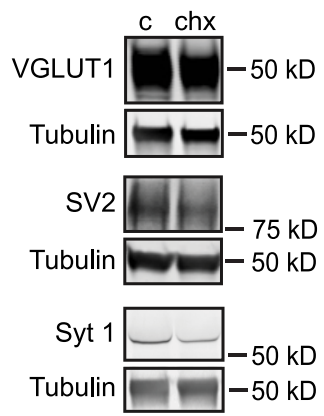

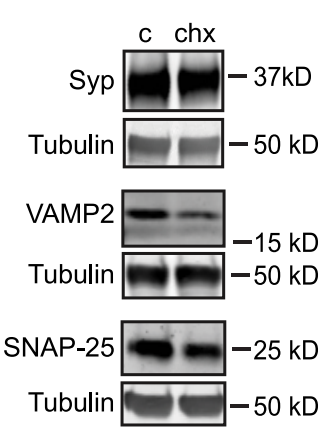

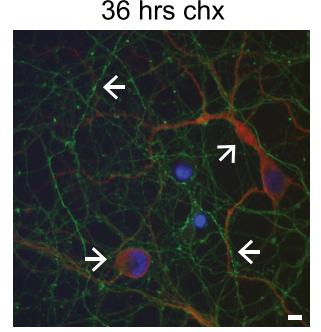

B

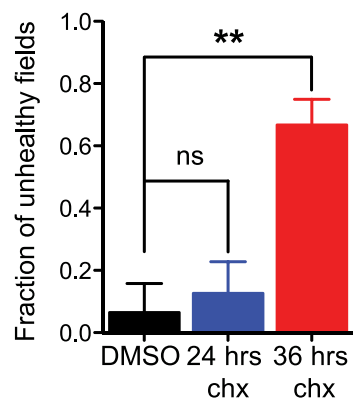

D

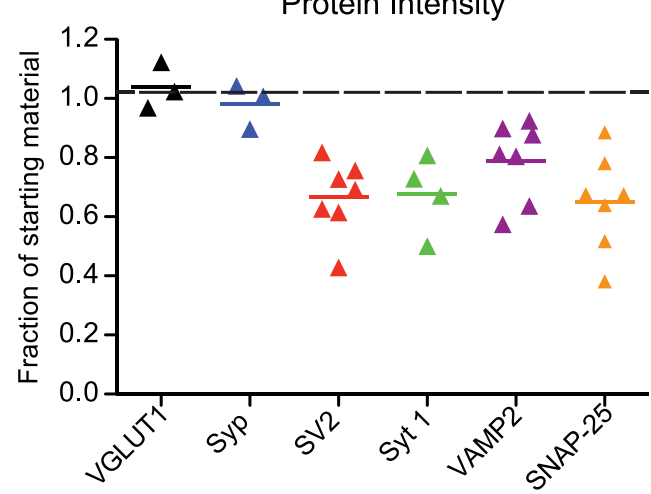

F Neuronal Activity

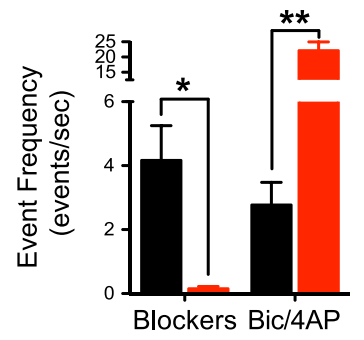

I

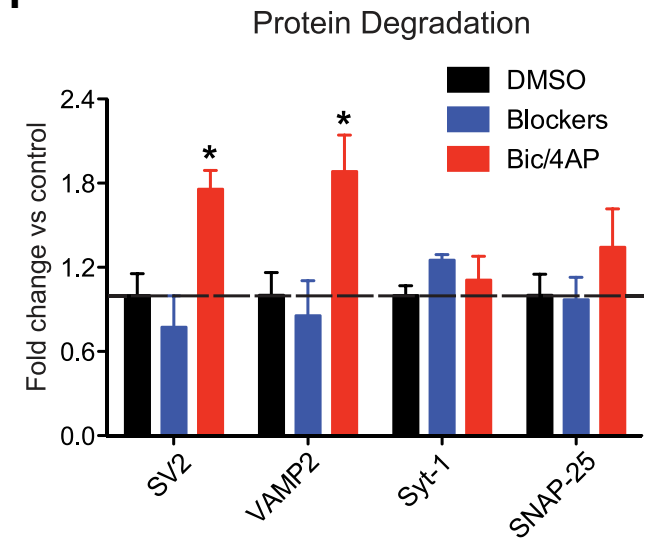

Figure 1. Neuronal activity drives the degradation of a subset of SV-associated proteins. A, Representative images from 14 DIV neurons treated with DMSO or cycloheximide for 24 or $36 \mathrm{~h}$, immunostained with Tau antibodies to label axons, MAP2 antibodies to label dendrites, and mounted with DAPI to label nuclei. Arrows in $36 \mathrm{~h}$ panel indicate the characteristics of cell health that were scored for in $\boldsymbol{B}$, including enlarged cell bodies, blebbing dendrites, and axonal beading. Tau immunostaining becomes weaker following cycloheximide treatment due to protein synthesis inhibition. White scale bar, $10 \mu \mathrm{m} . \boldsymbol{B}$, Quantification of neuronal health based on nuclear and process morphology per field of view (for details, see Materials and Methods; $n=5-7$ fields/condition). ${ }^{*} p<0.05$ (two-tailed $t$ test). C, Representative immunoblots of SV membrane proteins (VGLUT1, Synaptophysin [Syp], SV2, Synaptotagmin1 [Syt 1], VAMP2) and SNAP-25, with corresponding tubulin loading controls, from lysates of 14 DIV neurons treated for $24 \mathrm{~h}$ with either DMSO (c) or cycloheximide (chx). D, Quantification of protein intensity after $24 \mathrm{~h}$ of cycloheximide treatment, normalized to tubulin and reported as a fraction of the DMSO control intensity (starting material). Colored lines indicate averages. Each triangle represents one experiment. Black dotted line indicates no change in fractional degradation. $E$, Representative traces of 14 DIV neurons before and after application (indicated by black line) of $50 \mu \mathrm{m}$ AP5/10 $\mu \mathrm{M}$ CNQX/0.5 $\mu \mathrm{m}$ tetrodotoxin (blockers) to inhibit activity, or $40 \mu \mathrm{m}$ bicuculline/50 $\mu \mathrm{m}$ 4-AP (bic/4AP) to stimulate activity. $\boldsymbol{F}$, Quantification of spontaneous EPSC frequency pretreatment and post-treatment with blockers or bic/4AP. $\boldsymbol{G}$, Representative immunoblots from 14 DIV neurons treated for $24 \mathrm{~h}$ with DMSO (c) or cycloheximide in the presence of additional DMSO or blockers. Blots (Figure legend continues.) 
SV membrane proteins do not all turn over at the same rate; therefore, SVs may not be degraded as discrete units.

For those SV proteins whose levels were reduced following $24 \mathrm{~h}$ cycloheximide treatment, we next evaluated whether their degradation was influenced by neuronal activity. Neurons were again treated for $24 \mathrm{~h}$ with DMSO or cycloheximide, this time in the presence of pharmacological agents that either block neuronal activity (the $\mathrm{Na}^{+}$channel blocker TTX, the NMDA receptor blocker APV, and the AMPA receptor blocker CNQX), or increase activity (the GABA receptor antagonist bicuculline and the voltage-gated $\mathrm{K}^{+}$channel blocker 4-aminopyridine; bic/4AP) (Ehlers, 2003; Tauskela et al., 2008; Wijayatunge et al., 2014). The efficacy of these agents was verified in 14 DIV neurons by recording and quantifying the frequency of spontaneous EPSCs before and after drug application. We found that TTX, APV, and CNQX (blockers) significantly decreased this number, whereas bic/4AP significantly increased it (Fig. 1E,F). The amounts of protein degradation were expressed as "fold change in degradation versus control" by dividing the activity conditions (blockers, Bic/4AP) by the DMSO control condition (see Materials and Methods). Faster protein degradation was expressed as an increase in fold change $(>1)$, and slower degradation by a decrease in fold change $(<1$; Fig. $1 G-I)$. Although the amounts of protein degradation were not significantly different between the DMSO control and blocker conditions (Fig. 1G,I; Table 3), we found that bic/ 4AP treatment significantly sped SV2 and VAMP2 degradation during the $24 \mathrm{~h}$ time course (by $\sim 2$-fold) but did not alter Syt1 or SNAP-25 degradation (Fig. 1H,I; Table 3). These interesting findings indicate that a subset of SV membrane proteins (VAMP2, SV2) is degraded in an activity-dependent manner. Such use-dependent turnover could be essential for removing SV proteins that become damaged/misfolded through repeated cycles of SV exocytosis/endocytosis, yet the underlying molecular mechanisms are unknown.

\section{The ESCRT pathway is required for activity-dependent SV protein degradation}

To identify the cellular pathway responsible for activity-dependent degradation of SV2 and VAMP2, we initially focused on the ESCRT pathway. The ESCRT pathway comprises a series of protein complexes (ESCRT-0, -I, -II, -III, and Vps4) that catalyze the formation of MVBs and the sorting of cargo into MVBs for delivery to lysosomes (Raiborg and Stenmark, 2009). To confirm that this pathway has a role in SV protein degradation, as previously reported (Uytterhoeven et al., 2011; Fernandes et al., 2014), we examined the fold change in SV2 and VAMP2 degradation in the presence of an shRNA against the ESCRT-0 component Hrs (shHrs). Hrs, the initial component of the ESCRT-0 complex that binds and recruits ubiquitinated protein substrates, appears to be required for the initiation of MVB formation (Schmidt and Teis, 2012). When expressed between 7 and 14 DIV, we found that

(Figure legend continued.) probed for SV2 and Syt1, or VAMP2 and SNAP-25, are shown with corresponding tubulin loading controls. $\boldsymbol{H}$, Representative immunoblots from 14 DIV neurons treated for $24 \mathrm{~h}$ with DMSO (c) or cycloheximide in the presence of additional DMSO or bic/4AP to stimulate neuronal activity, and probed for the same proteins as in $\mathbf{G}$. I, Quantification of protein degradation in each condition, expressed as the fold change versus DMSO control. Treatments that speed protein degradation are represented by an increase in fold change $(>1)$. Black dotted line indicates fractional degradation in the presence of DMSO control (black bar). For this and all subsequent bar graphs, data are mean \pm SEM. Student's two-tailed $t$ tests are used to calculate significance of each experimental condition versus control $(n \geq 3)$. ${ }^{* *} p<$ 0.01. ns, Not significant.
shHrs led to a $67.8 \pm 0.10 \%$ knockdown of Hrs protein (Fig. $2 A$ ) without any observable toxicity. Further, shHrs significantly attenuated SV2 and VAMP2 degradation compared with scRNA control (Fig. $2 B, C$ ), indicating that basal degradation of these proteins occurs through the ESCRT pathway. To bolster this finding, we repeated the experiment with an shRNA against TSG101, a component of the ESCRT-I complex that acts downstream of Hrs. Like shHrs, shTSG101 led to a relatively efficient $58.2 \pm 0.04 \%$ knockdown of TSG101 (Fig. $2 A$ ) and attenuated SV2 and VAMP2 degradation (Fig. 2D,E), indicating that the ESCRT pathway, and not just Hrs or the ESCRT-0 complex, facilitates the degradation of SV proteins. To assess whether this pathway also mediates the activity-dependent turnover of SV2 and VAMP2, neurons expressing scRNA or shHrs were treated with bic/4AP or DMSO vehicle control, and changes in protein degradation measured after $24 \mathrm{~h}$ cycloheximide treatment. We found that bic/4AP treatment again increased the degradation of SV2 and VAMP2 by nearly twofold in scRNA-expressing neurons (Fig. $2 F, G$ ). In contrast, shHrs-expressing neurons exhibited no bic/4AP-mediated increases in SV2 or VAMP2 degradation (Fig. 2F,G). These findings indicate that the ESCRT pathway is essential for basal and activity-dependent turnover of these SV proteins.

\section{ESCRT proteins undergo activity-dependent recruitment to SV pools}

Although the ESCRT pathway has previously been linked to SV protein turnover (Uytterhoeven et al., 2011; Fernandes et al., 2014), the localization of ESCRT proteins in axons, and their behavior in response to neuronal activity, has not been investigated. Based on our findings, we hypothesized that ESCRT proteins would localize to axons and associate with SV pools and that neuronal activity would increase this association. To test this concept, we transduced neurons with mCh-tagged Hrs (ESCRT-0 complex) or CHMP2B (ESCRT-III complex; MVB marker) on 9 DIV, and treated neurons with either DMSO or $\mathrm{bic} / 4 \mathrm{AP}$ for $12 \mathrm{~h}$ on $14 \mathrm{DIV}$. Neurons were then fixed and immunostained for VAMP2 to label SV pools. The percentage colocalization of mCh-Hrs or CHMP2B-mCh puncta with VAMP2, and the number of puncta per unit length of axon, were quantified and compared in the presence or absence of bic/4AP. Although $\sim 40 \%$ of mCh-Hrs puncta colocalized with VAMP2 at baseline, treatment with bic/4AP increased this value to nearly $75 \%$ (Fig. $3 A, C)$. At the same time, increased neuronal activity led to nearly four times as many mCh-Hrs puncta/unit length axon compared with control neurons (Fig. $3 A, D$ ). We also observed a striking change in the localization of CHMP2B-mCh following bic/4AP treatment. In control neurons, $\mathrm{CHMP} 2 \mathrm{~B}-\mathrm{mCh}$ puncta rarely appeared in axons. However, following bic/4AP treatment, multiple CHMP2B-mCh puncta were present in axons, and $\sim 35 \%$ of these colocalized with VAMP2 (Fig. $3 B, C$ ). These data show that neuronal activity dramatically increases the entry of ESCRT proteins into axons and their association with SV pools.

To determine whether these SV pools were synaptic, and to examine the precise localization of the ESCRT proteins relative to SV pools, we performed high-resolution imaging of neurons transduced with mCh-tagged Hrs or CHMP2B, treated with bic/ $4 \mathrm{AP}$, and immunostained with VAMP2 and the postsynaptic protein Homer1. Hrs and CHMP2B puncta associated with both synaptic and nonsynaptic VAMP2 clusters, with nearly twice as many puncta at synaptic clusters based on their colocalization with Homer1 (67\% synaptic vs 33\% nonsynaptic for $\mathrm{Hrs,} 68 \%$ synaptic vs $32 \%$ nonsynaptic for CHMP2B; Fig. $3 E-G$ ). More- 
A

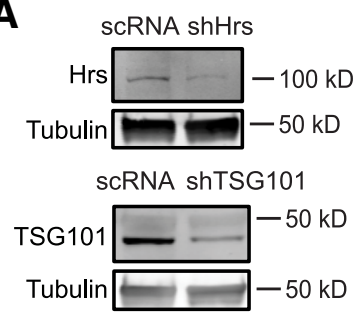

D

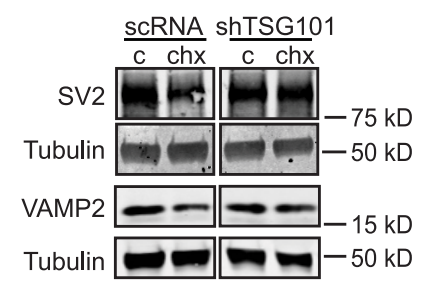

B

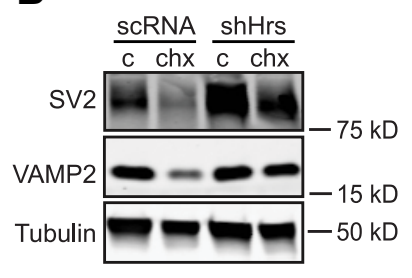

E Protein Degradation
C Protein Degradation

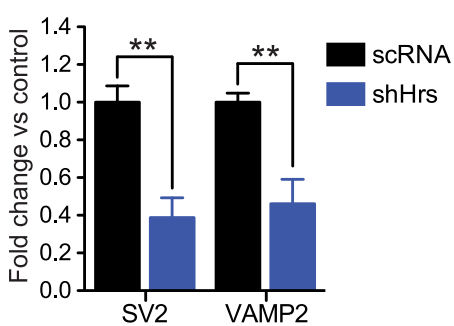

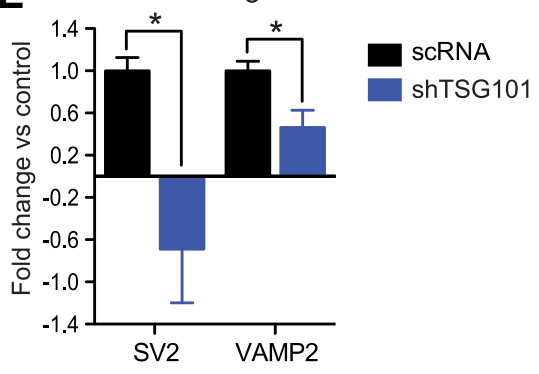

$\mathbf{F}$

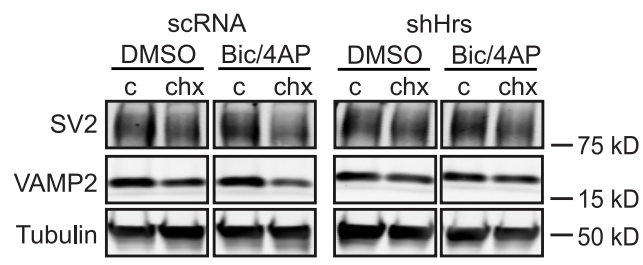

G Protein Degradation

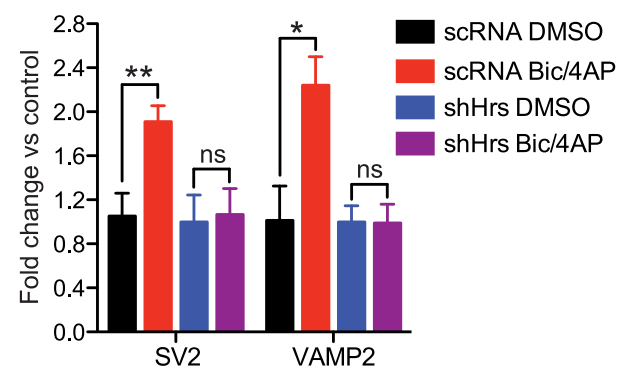

Figure 2. The ESCRT pathway is required for basal and activity-dependent SV protein degradation. $\boldsymbol{A}$, Representative immunoblots of Hrs, TSG101, and corresponding tubulin loading controls from 14 DIV neurons transduced with scRNA, shHrs, or shTSG101. Knockdown efficacy is $67.8 \pm 0.1 \%$ of scRNA control for shHrs, and $58.2 \pm 0.04 \%$ of control for shTSG101. B, Representative immunoblots of SV2, VAMP2, and corresponding tubulin loading control, from 14 DIV neurons transduced with scRNA or shHrs and treated for $24 \mathrm{~h}$ with DMSO (c) or cycloheximide. C, Quantification of the fold change in degradation of SV2 and VAMP2 in the presence of shHrs compared with scRNA control $(n=4)$. ${ }^{* *} p<0.01$. D, Representative immunoblots of SV2, VAMP2, and corresponding tubulin loading controls, from 14 DIV neurons transduced with scRNA or shTSG101 and treated for $24 \mathrm{~h}$ with DMSO (c) or cycloheximide. E, Quantification of fold change in degradation of SV2 and VAMP2 in the presence of shTSG101 compared with scRNA control $(n=4) .{ }^{*} p<0.05$. $\boldsymbol{F}$, Representative immunoblots of SV2, VAMP2, and corresponding tubulin loading controls, from 14 DIV neurons transduced with scRNA or shHrs and treated for $24 \mathrm{~h}$ with DMSO (c) or cycloheximide in the presence of additional DMSO or bic/4AP. G, Quantification of fold change in degradation of SV2 and VAMP2 in the presence of scRNA or shHrs, $+/$ - activity. DMSO control is set to 1 for each condition (black bars represent scRNA; blue bars represent shHrs), and bic/4AP treatment is expressed as fold change versus DMSO control for that condition $(n=6) .{ }^{*} p<0.05$. ns, Not significant.

over, Hrs and CHMP2B puncta typically exhibited partial, but not complete, overlap with VAMP2 clusters (Fig. $3 E, F$ ), suggesting that they could represent distinct vesicle populations or associate with subsets of SVs.

Given the activity-dependent accumulation of ESCRT proteins at presynaptic boutons, we were curious to elucidate the underlying molecular mechanism. Based on their key roles in trafficking proteins into the endocytic pathway (Stenmark, 2009), we presumed that Rab GTPases would play a role in this process. More than half of the 60 mammalian Rabs can be copurified with SV pools (Takamori et al., 2006; Pavlos and Jahn, 2011), and several of these, including Rabs 5, 10, 14, 21, and 35, associate with early and recycling endosomes in neurons and other cell types (Fischer von Mollard et al., 1994; Junutula et al., 2004; Babbey et al., 2006; Sato et al., 2008; Pavlos and Jahn, 2011; Uytterhoeven et al., 2011). We hypothesized that one or more of these putative endocytic Rabs would mediate SV protein degradation. Moreover, Hrs also localizes to early endosomes (Komada and Soriano, 1999; Sato et al., 2008) and is the initial component of the ESCRT pathway, leading us to further hypoth- esize that it could interact with one or more of the endocytic Rabs to mediate SV protein degradation. To test for Hrs/Rab interactions, we performed coimmunoprecipitation assays in HEK293T cells expressing Flag-Hrs and HA-tagged Rabs 5, 10, 14, 21, or 35. Interestingly, we found that Rabs 10, 14, and 35 were efficiently coimmunoprecipitated by Flag-Hrs, whereas Rabs 5 and 21 were not (Fig. $4 A, B$ ). These findings demonstrate that a subset of endocytic Rabs interact with Hrs and may participate in SV protein degradation.

\section{Rab35 interacts with Hrs and stimulates SV protein degradation}

We next tested whether overexpression of any of these endocytic Rabs could stimulate SV2 and VAMP2 degradation in hippocampal neurons. Multiple groups have reported that overexpression of wild-type small GTPases induces phenotypes that reflect their activation (Brondyk et al., 1993; Li and Stahl, 1993; McCaffrey et al., 2001; Ravikumar et al., 2008). Furthermore, it was recently demonstrated that the conventional "constitutively active" mutants are not active for all Rabs, including Rab35 (Langemeyer et 
A

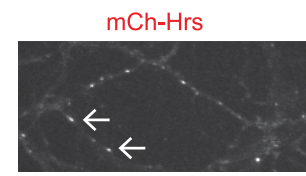

Bic/4AP

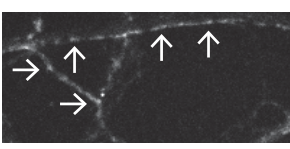

B

DMSO

CHMP2B-mCh

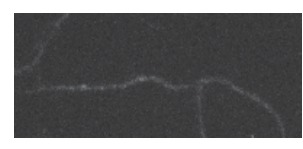

$\mathrm{Bic} / 4 \mathrm{AP}$

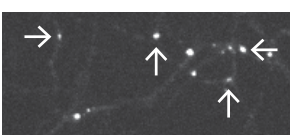

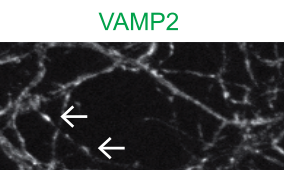

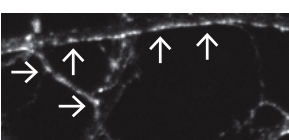

VAMP2
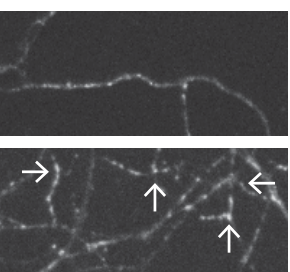

Tau
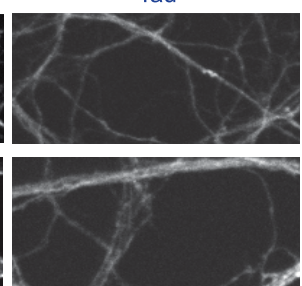

Tau
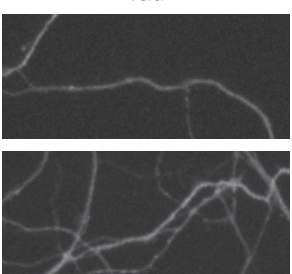
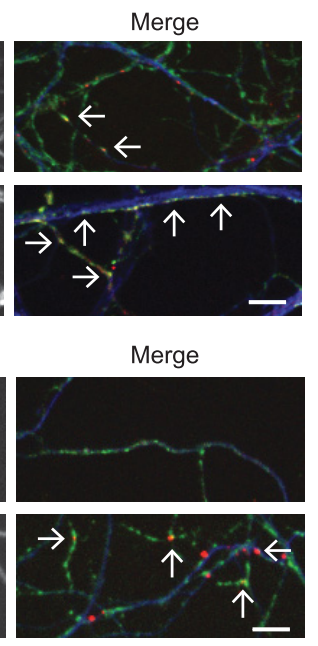

C Colocalization with VAMP2

D Hrs Axonal Localization
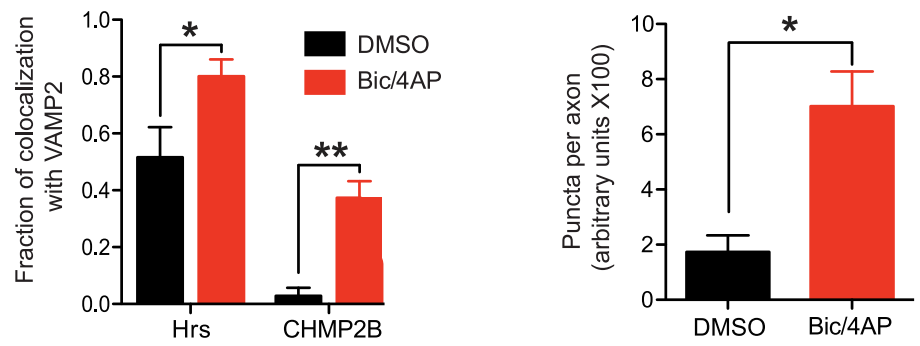

E
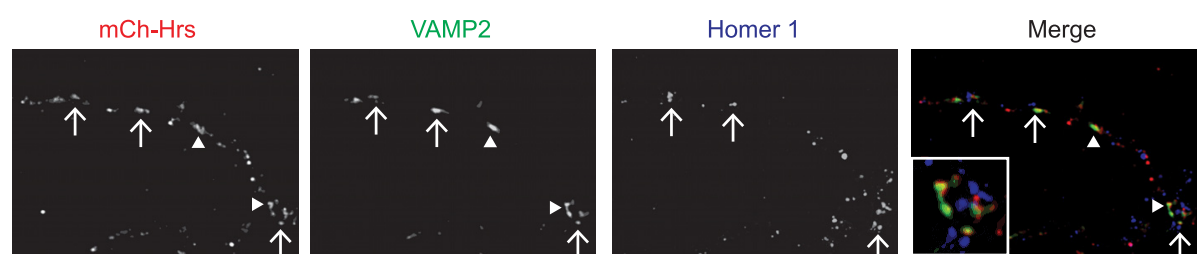

$\mathbf{F}$
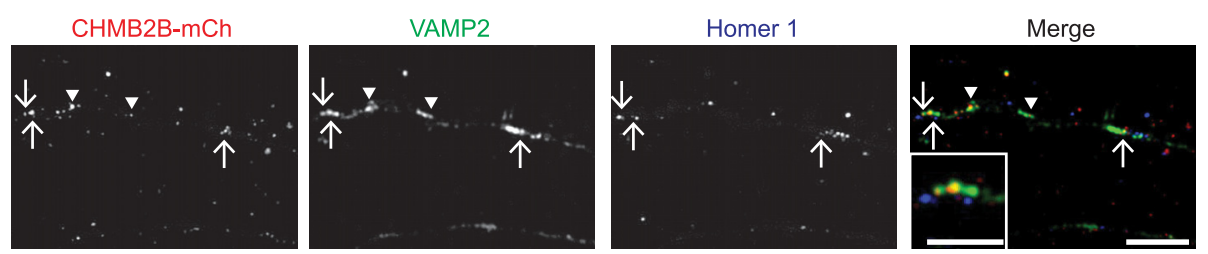

G

ESCRT Localization

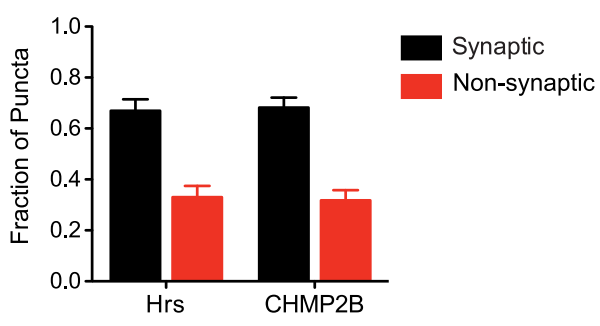

Figure 3. Neuronal activity recruits ESCRT proteinsto SV pools. A, Images of neurons transduced with mCh-Hrs, treated with DMSO or bic/4AP for 12h, then fixed and immunostained againstVAMP2 and Tau. Arrows indicate VAMP2 puncta that colocalize with $\mathrm{mCh}$-Hrs in axons. Scale bar, $10 \mu \mathrm{m} . B$, Images of neurons transduced with CHMP2B-mCh, treated as in $A$, then fixed and immunostained against VAMP2 and Tau. Arrows indicate VAMP2 puncta that colocalize with CHMP2B-mCh in axons. Scale bar, $10 \mu \mathrm{m}$. C, Quantification of the fraction of Hrs or CHMP2B puncta colocalized with VAMP2 (for Hrs: $n=4$ DMSO, $n=$ $8 \mathrm{bic} / 4 \mathrm{AP}$ from 3 replicate weeks, $\sim 30$ puncta/image). ${ }^{*} p<0.05$. For CHMP2B: $n=5$ for DMSO, $n=8$ for bic/4AP from 2 replicate weeks, $\sim 10$ puncta/image. ${ }^{* *} p<0.01 . D$, Quantification of the number of Hrs puncta per unit length of axon (arbitrary units; $n=4 \mathrm{DMSO}, n=5 \mathrm{bic} / 4 \mathrm{AP}, \sim 30$ puncta/image, similar results obtained for 3 independent experiments). ${ }^{*} p<0.05$. E, Super-resolution images of neurons transduced with $\mathrm{mCh}$-Hrs, treated as in $\boldsymbol{A}$, and immunostained against VAMP2 and Homer1. Arrowhead indicates nonsynaptic $\mathrm{mCh}$-Hrs puncta. Arrows indicate synaptic puncta based on colocalization with Homer. Inset, Higher-magnification view of a synaptic site. $F$, Super-resolution images of neurons transduced with CHMP2B-mCh, treated as in $A$, and immunostained against VAMP2 and Homer. Arrowheads indicate nonsynaptic CHMP2B-mCh puncta. Arrows indicate synaptic puncta. Inset, Higher-magnification view of a synaptic site. Scale bar, $5 \mu \mathrm{m}$; inset, $2.5 \mu \mathrm{m}$. G, Quantification of the synaptic and nonsynaptic fractions of Hrs and CHMP2B puncta in axons following neuronal activity ( $\sim 200$ puncta for Hrs, $\sim 120$ puncta for CHMP2B). 
A

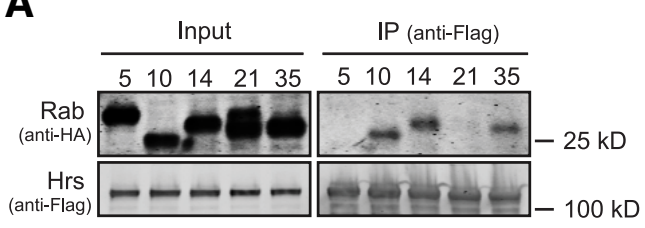

B

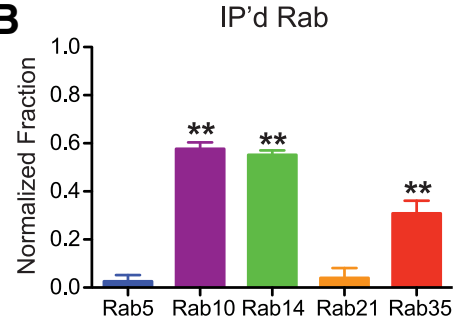

C

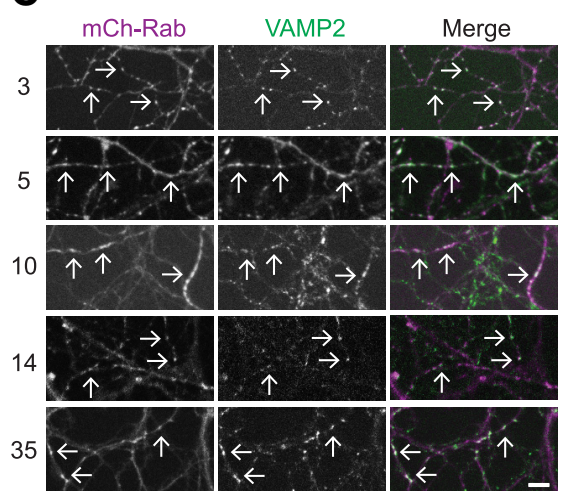

H

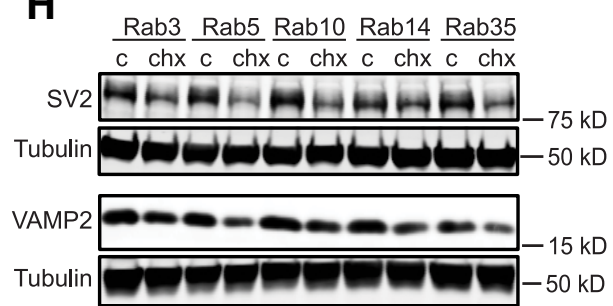

D

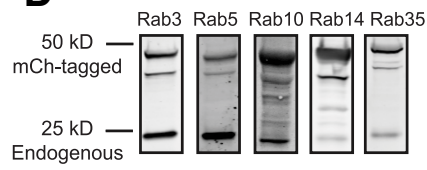

$\mathbf{F}$

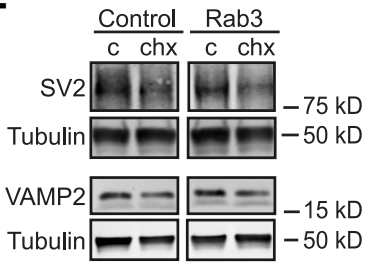

E Protein Overexpression

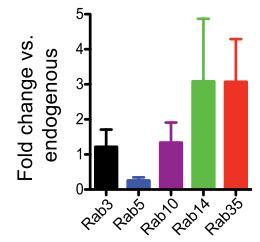

G

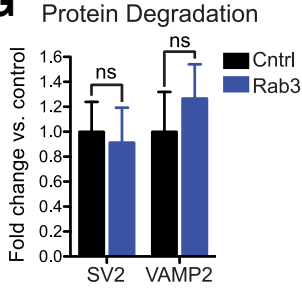

I

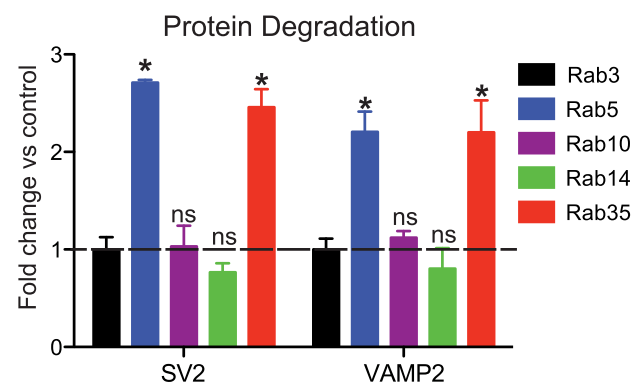

$\mathbf{K}$

Protein Degradation

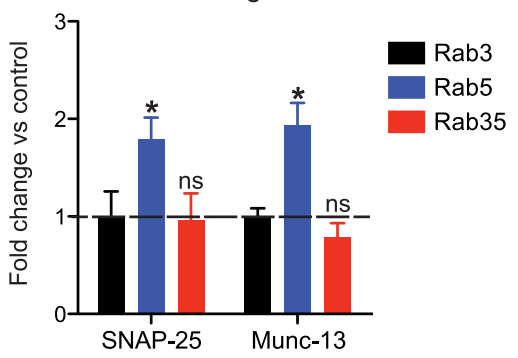

Figure 4. A subset of endocytic Rabs interact with Hrs and/or drive SV protein degradation. A, Representative immunoblot of HEK cell lysates expressing HA-Rab5, 10, 14, 21, or 35 and Flag-Hrs, subject to IP with Flag antibody and probed with HA or Flag antibodies. B, Quantification of HA-Rab intensity in the eluate, normalized to input intensity and Flag-Hrs intensity in the eluate $(n=3)$. ${ }^{* *} p<0.01$. C, Representative images from 14 DIV neurons transduced with mCh-tagged Rab3, Rab5, Rab10, Rab14, or Rab35 and immunostained with VAMP2 antibodies. Arrows indicate VAMP2 puncta in axons expressing the mCh-Rab. Scale bar, $10 \mu \mathrm{m}$. D, Immunoblots from 14 DIV neurons transduced with mCh-tagged Rab3, Rab5, Rab10, Rab14, or Rab35, and probed for the respective Rab. $\boldsymbol{E}$, Quantification of $\mathrm{mCh}$-tagged Rab intensity, expressed as fold change versus endogenous Rab level $(n=3)$. $\boldsymbol{F}$, Immunoblots of SV2, VAMP2, and tubulin loading control, from $14 \mathrm{DIV}$ neurons untransduced (control) or transduced with mCh-Rab3 and treated for $24 \mathrm{~h}$ with either DMSO (c) or cycloheximide. G, Quantification of the fold change in degradation of SV2 and VAMP2 for Rab3 versus untransduced control ( $n=3$ or 4 independent experiments). $\boldsymbol{H}$, Representative immunoblots of SV2, VAMP2, and tubulin loading control, from 14 DIV neurons transduced with $\mathrm{mCh}$-tagged Rab3, Rab5, Rab10, Rab14, or Rab35, and treated as in F.I, Quantification of the fold change in degradation of SV2 and VAMP2 for each Rab versus Rab3 control ( $n=3$ or 4 independent experiments). ${ }^{*} p<0.05$. J, Representative immunoblots of SNAP-25, Munc-13, and corresponding tubulin loading controls, from 14 DIV neurons transduced with mCh-Rab3, mCh-Rab5, or mCh-Rab35, and treated as in $\boldsymbol{F}$. $\boldsymbol{K}$, Quantification of the fold change in degradation of SNAP-25 and Munc-13 intensity for each Rab versus Rab3 control $(n=3) .{ }^{*} p<0.05$. ns, Not significant.

al., 2014). We therefore used wild-type rather than constitutively active Rabs for our studies, anticipating that their relatively modest overexpression by lentivirus would lead to phenotypes reflecting their activated states while at the same time minimizing the toxicity often associated with Rab overexpression (Star et al.,
2005). Indeed, when neurons were transduced with mCherrytagged Rabs $(5,10,14$, or 35) for $4 \mathrm{~d}$ before cycloheximide-chase experiments, we found that they localized to axons and presynaptic boutons and were overexpressed $\sim 1$ - to 3 -fold over endogenous levels (Fig. 4C-E) with no observable toxicity. Lysates from 
Rab-expressing neurons were collected and immunoblotted for SV2 and VAMP2, and the fold change in protein degradation calculated for each Rab. Rab3, an SV-associated Rab with a wellcharacterized role in SV exocytosis (Yu et al., 2008; Pavlos and Jahn, 2011), served as our control in these studies as its overexpression did not alter SV protein degradation compared with untransduced neurons (Fig. $4 F, G$ ). Similarly, we found that Rabs 10 and 14 did not alter SV2 or VAMP2 degradation over the $24 \mathrm{~h}$ period (Fig. $4 H, I$ ). In contrast, overexpression of Rabs 5 and 35 increased the amount of SV2 and VAMP2 degradation by greater than twofold (Fig. 4H,I). Both of these Rabs were previously reported to have roles in SV recycling (Shimizu et al., 2003; Wucherpfennig et al., 2003; Uytterhoeven et al., 2011), and Rab35 was recently implicated in the turnover/replenishment of SV proteins at the Drosophila neuromuscular junction (Uytterhoeven et al., 2011; Fernandes et al., 2014). However, as Rab35 interacts with Hrs and Rab5 does not (Fig. $4 A, B$ ), we investigated the specificity of these Rabs for SV integral membrane protein degradation. We found that Rab5 overexpression sped the degradation of several presynaptic proteins, including SNAP-25 (a plasma membrane-associated protein) and Munc13 (an active zone protein), whereas Rab35 only sped the degradation of SV2 and VAMP2 (Fig. 4J,K). These findings suggest that the Rab35/Hrs interaction is important for defining the specificity of the degradative pathway for particular SV integral membrane proteins.

To confirm that Rab35 targets the synaptic pool of SV proteins for degradation, we measured the levels of presynaptic/axonal VAMP2 by quantitative immunofluorescence microscopy. We compared the steady-state levels and the levels of VAMP2 remaining after $24 \mathrm{~h}$ of cycloheximide treatment in axons from 14 DIV neurons expressing mCh-Rab35 versus mCh-Rab3 control. Average fluorescence intensities of VAMP2 puncta in axons expressing Rab3 or Rab35 were quantified and presented as a fraction of the average intensity in Rab3-expressing axons. We found that these values were not significantly different between Rab3 and Rab35-expressing neurons (Fig. 5A,B), indicating that this assay was not sensitive enough to detect subtle changes in VAMP2 steady-state levels. However, similar to our immunoblot experiments, we found that VAMP2 levels were significantly lower $24 \mathrm{~h}$ after cycloheximide treatment in axons expressing Rab35 compared with those expressing Rab3 (Fig. 5A,B). To further confirm these findings, we used the SNAP-tag system for quantitative fluorescence pulse-chase analysis (Bodor et al., 2012). The SNAP-tag is a self-labeling enzyme that allows for covalent attachment of an exogenously applied fluorescent compound to a protein of interest. We designed a dual SNAP- and Flag-tagged VAMP2, which was coexpressed in neurons with either mCh-Rab3 or mCh-Rab35. On 13 DIV, neurons were incubated for $30 \mathrm{~min}$ with the SNAP-tag substrate benzylguanineOregon Green (BG-OG, New England Biolabs), washed, and then returned to normal media. Neurons were subsequently fixed at two time points after labeling (15 and $48 \mathrm{~h}$ ) and immunostained with anti-Flag antibody, allowing us to measure both the "pulsed" fraction of VAMP2-SNAP (via BG-OG intensity) and the total pool of VAMP2-SNAP (via Flag intensity) present at each time. After $15 \mathrm{~h}$, we saw no significant differences in the intensity of BG-OG labeling, the intensity of Flag immunostaining, or the colocalization of BG-OG with Flag immunostaining in Rab3 versus Rab35-expressing neurons, although there was a trend toward decreased BG-OG/Flag colocalization in Rab35expressing neurons (Fig. 5C,D). These results indicate that Rab35 expression does not lead to lower levels of VAMP2-SNAP expres- sion or initial BG-OG labeling. However, after $48 \mathrm{~h}$, both the intensity of BG-OG labeling and the colocalization of BG-OG with Flag immunostaining were significantly reduced in Rab35expressing neurons compared with Rab3 controls, whereas total VAMP2-SNAP levels were not altered (Fig. 5C,E). These data confirm that Rab35 stimulates degradation of the synaptic pool of SV proteins.

\section{Rab35 is necessary for activity-dependent SV protein degradation upstream of the ESCRT pathway}

We next investigated whether Rab35 has a key role in the activitydependent degradation of SV2 and VAMP2. First, we tested whether Rab35 is necessary for SV protein degradation under basal conditions. Using the cycloheximide-chase assay in neurons transduced with a published shRNA that reduces Rab35 protein levels by $64.7 \pm 0.04 \%$ (shRab35; Fig. 6A) (Allaire et al., 2010), we found that Rab35 knockdown significantly attenuated the degradation of SV2 and VAMP2 compared with a scrambled control shRNA (scRNA; Fig. 6B,C). Coexpression of shRNAresistant Rab35 rescued this attenuation of SV protein degradation by shRab35 (Fig. 6D,E).

We subsequently examined whether Rab35 was necessary for activity-dependent SV protein degradation. As in previous experiments, neurons expressing scRNA and shRab35 were treated with bic/4AP to increase activity, and protein degradation was monitored after $24 \mathrm{~h}$ cycloheximide treatment. Remarkably, we found that the ability of bic/4AP to stimulate SV2 and VAMP2 degradation was nearly abolished in neurons expressing shRab35 (Fig. 6F, G). Furthermore, Rab35 does not stimulate SV protein degradation by increasing neuronal activity, as blocking activity in Rab35-expressing neurons did not significantly alter the degradation of SV2 and VAMP2 compared with Rab35 overexpression alone (Fig. $6 H, I$ ). These findings demonstrate that activity-dependent SV protein turnover is dependent on Rab35.

To determine whether Rab35 acts upstream of the ESCRT pathway, we measured the degradation of SV2 and VAMP2 in neurons coexpressing scRNA or shHrs and mCh-Rab35. As anticipated, Rab35-mediated degradation of SV2 and VAMP2 was significantly attenuated in shHrs-expressing neurons (Fig. $7 A, B)$. Moreover, average VAMP2 immunofluorescence intensity was increased by $40 \%$ in shHrs/mCh-Rab35 versus scRNA/ mCh-Rab35 expressing neurons following $24 \mathrm{~h}$ cycloheximide treatment (Fig. 7C,D). We also performed these experiments in neurons expressing mCh-Rab35 and scRNA or shTSG101 and found similar results by immunoblotting and quantitative immunofluorescence (Fig. 7E-H). Together, these data demonstrate that Rab35 acts upstream of the ESCRT pathway to mediate degradation of SV proteins.

\section{Hrs is an effector of Rab35}

Our coimmunoprecipitation experiments demonstrated an interaction between Rab35 and Hrs (Fig. 4A,B). To further characterize the specificity of this interaction, we coexpressed EGFPRab35 together with a series of mCh-tagged ESCRT proteins in HEK293T cells. We found that EGFP-Rab35 robustly colocalized with Hrs, but not with TSG101 or CHMP2B (Fig. 8A). Next, we performed coimmunoprecipitation assays in HEK293T cells expressing HA-Rab35 together with a similar series of mCh-tagged ESCRT proteins. HA-Rab35 coprecipitated robustly with Hrs, but only weakly with STAM (another ESCRT-0 component), TSG101, and CHMP2B (Fig. 8B). Given the specificity of the Rab35-Hrs interaction, we next investigated whether Hrs was a direct effector of Rab35. Effectors are recruited by active (GTP- 
A

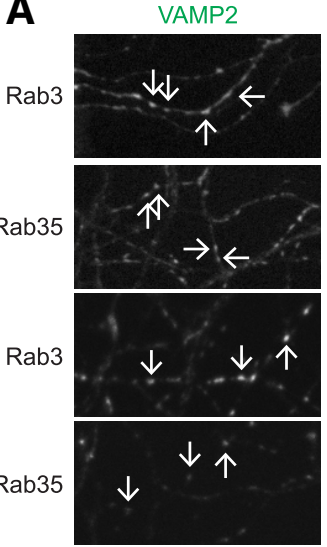

C
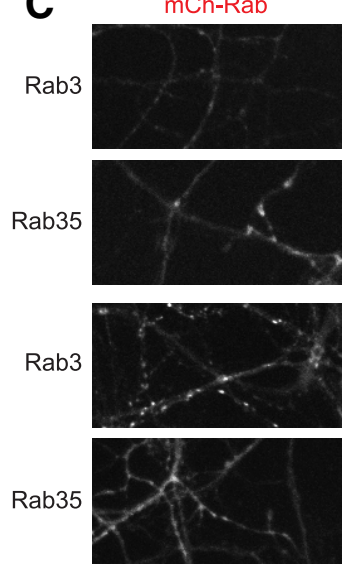

D

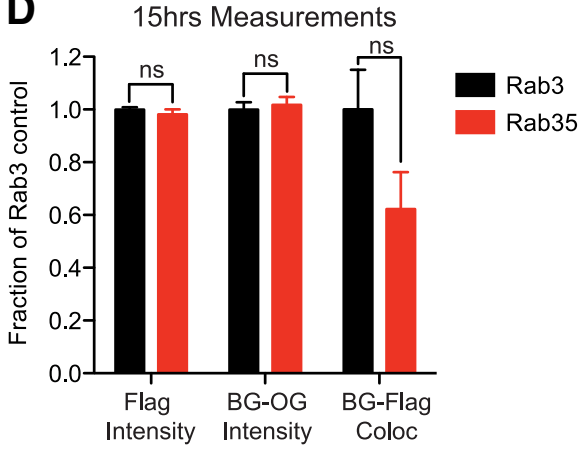

mCh-Rab

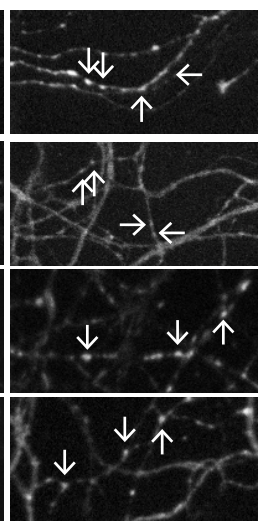

Flag
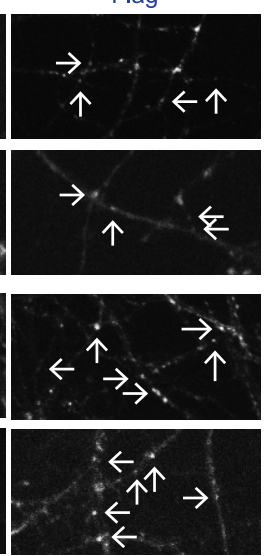

Coloc
Merge

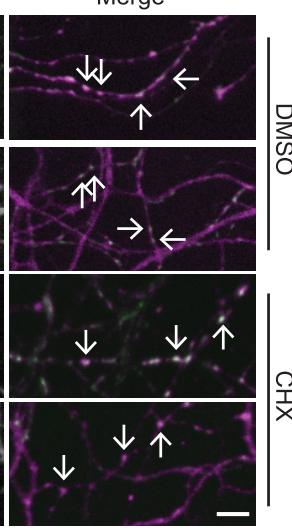

B

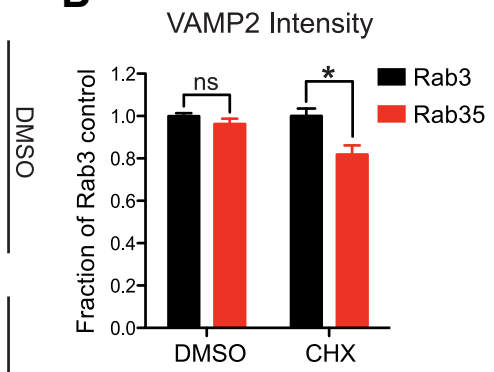

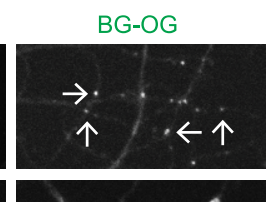
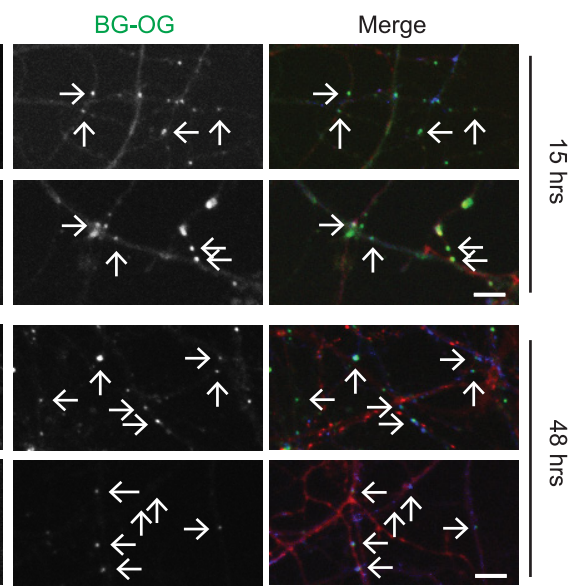

$\overrightarrow{0}$

$\stackrel{+\infty}{\infty}$

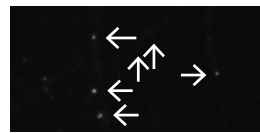

菅

E

48hrs Measurements

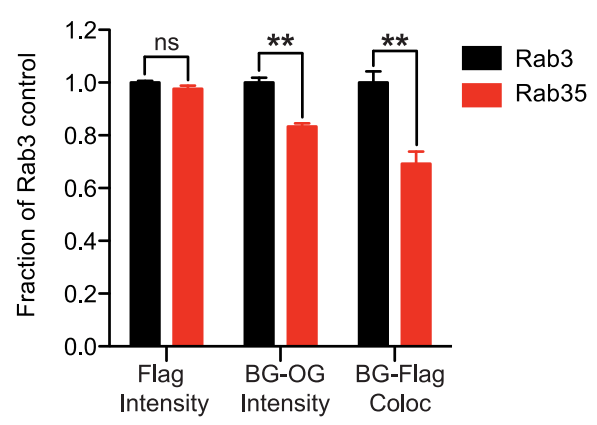

Figure 5. Rab35 drives SV protein degradation at synapses. A, Representative images from 14 DIV neurons transduced with either mCh-Rab3 or mCh-Rab35, treated for $24 \mathrm{~h}$ with DMSO or cycloheximide and immunostained with VAMP2 antibodies. Arrows indicate VAMP2 puncta in axons expressing mCh-Rab3 or mCh-Rab35. Scale bar, $10 \mu \mathrm{m}$. $\boldsymbol{B}$, Quantification of the average fluorescence intensity of VAMP2 puncta, normalized to Rab3 ( $n=9$ images/condition; 3 replicate weeks, each with 3 images/condition, $\sim 100$ puncta/image). ${ }^{*} p<0.05$. C, Representative images from neurons expressing VAMP2-SNAP and either mCh-Rab3 or mCh-Rab35, fixed 15 or $48 \mathrm{~h}$ after BG-0G labeling and immunostained with Flag antibodies. Arrows indicate VAMP2 puncta detected with Flag (blue) in axons expressing mCh-Rab3 or mCh-Rab35 (red). Scale bar, $10 \mu \mathrm{m}$. D, Quantification of the average fluorescence intensity of Flag staining ( $n=5$; $\sim 100$ puncta/image), BG-0G labeling ( $n=10 ; \sim 100$ puncta/image), and the fraction of BG-0G puncta that colocalize with Flag ( $n=6$ for Rab3, $n=5$ for Rab35; $\sim 75$ puncta/image) in each condition normalized to Rab3 at the $15 \mathrm{~h}$ time point. $\boldsymbol{E}$, Quantification as in $\boldsymbol{D}$ for Flag staining $(n=5 ; \sim 100$ puncta/image), BG-OG labeling $(n=7$ images/condition; $\sim 100$ puncta/image; similar results obtained for 3 independent experiments; $\left.{ }^{* *} p<0.01\right)$, and BG-0G puncta colocalization $\left(n=19\right.$ images/condition from 3 replicate weeks, $\sim 75$ puncta/image; $\left.{ }^{* *} p<0.01\right)$ for the $48 \mathrm{~h}$ time point. ns, Not significant.

bound) Rabs to perform the relevant downstream vesicle sorting, uncoating, trafficking, tethering, or fusion steps (Stenmark, 2009) Here, we performed coimmunoprecipitation assays in HEK cell lysates expressing HA-Rab35 and Flag-Hrs, and subsequently incubated with either GDP or GTP $\gamma$ S. We observed that significantly more HA-Rab35 was coprecipitated by Flag-Hrs in the presence of GTP $\gamma \mathrm{S}$ than GDP, as expected whether Hrs is a Rab35 effector (Fig. 8C,D). To confirm these findings, we performed pull-down experiments with GST-Rab35 loaded with
GDP or GTP $\gamma S$, coupled to glutathione-agarose beads, and incubated with HEK cell lysate-expressing Flag-Hrs. We again found that GST-Rab35-GTP pulled down significantly more Flag-Hrs (Fig. 8E,F), consistent with the coimmunoprecipitation results. Thus, our data clearly show that Hrs is an effector of Rab35, providing a direct mechanistic link between Rab35 and the ESCRT pathway.

Based on this finding, we hypothesized that Rab35 would recruit Hrs to SV pools to initiate ESCRT complex formation. Be- 
A

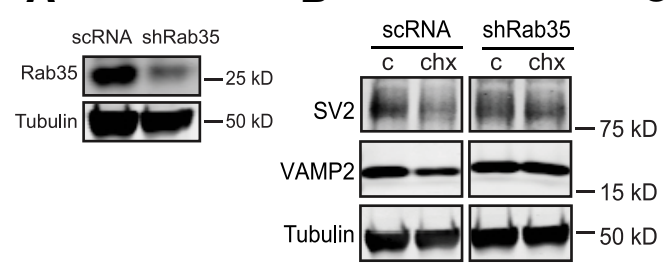

D

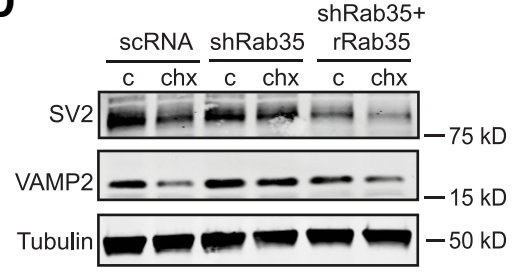

F

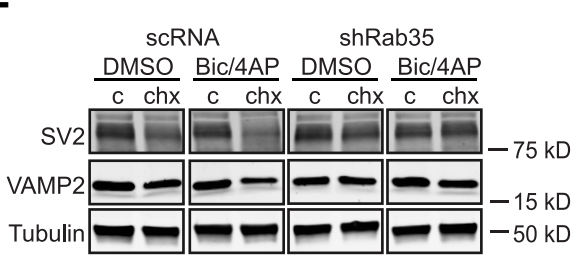

H

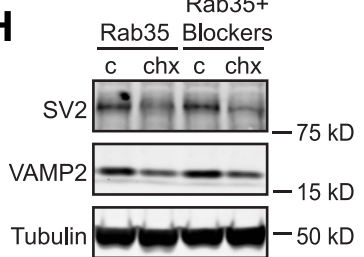

c

E
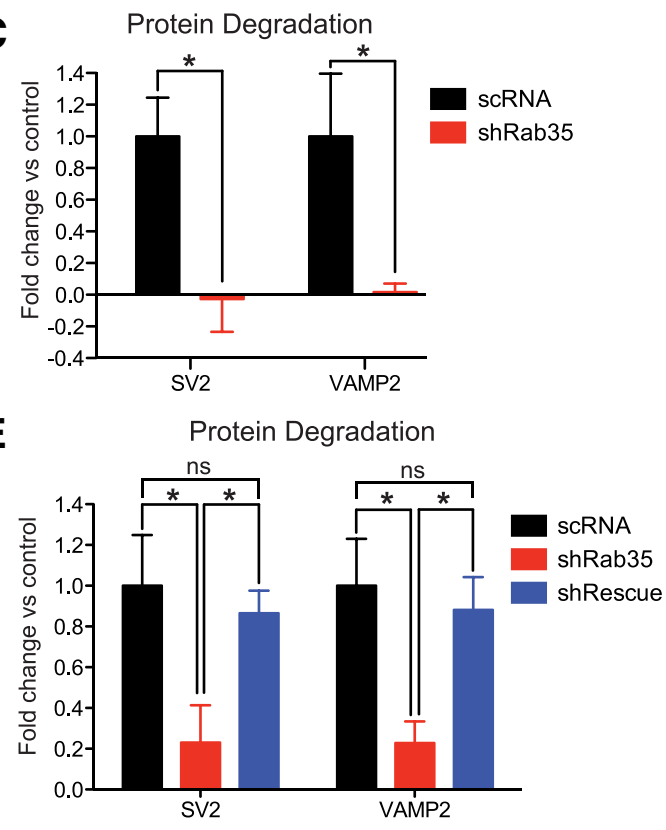

G
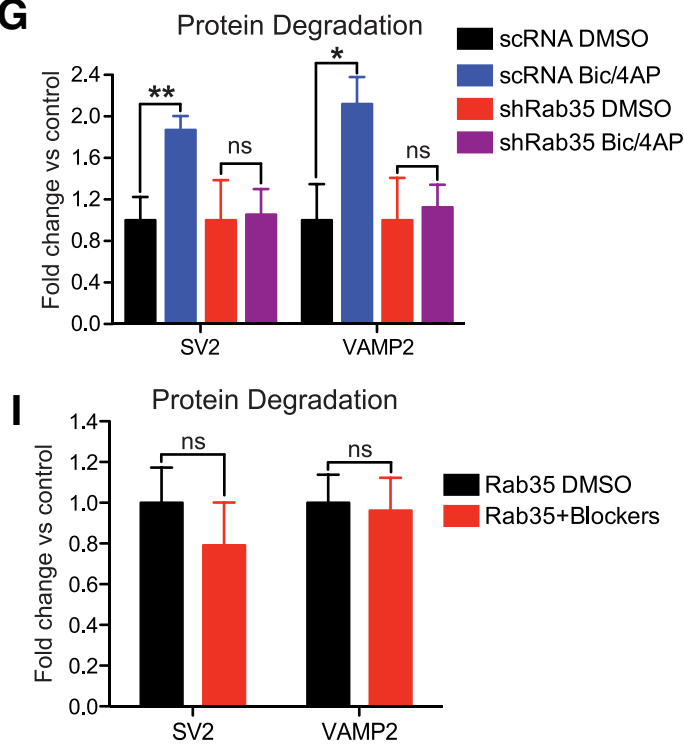

Figure 6. Knockdown of Rab35 inhibits basal and activity-dependent SV protein degradation. $\boldsymbol{A}$, Representative immunoblot of Rab35 and tubulin loading control from 14 DIV neurons transduced with scRNA or shRab35. Knockdown efficacy of Rab35 is $64.7 \pm 0.04 \%$ of scRNA control. $B$, Representative immunoblots of SV2, VAMP2, and corresponding tubulin loading control, from 14 DIV neurons transduced with scRNA or shRab35 and treated for $24 \mathrm{~h}$ with DMSO (c) or cycloheximide. C, Quantification of the fold change in degradation of SV2 and VAMP2 for shRab35 versus scRNA control ( $n=3$ or 4). ${ }^{*} p<0.05$. D, Representative immunoblots of SV2, VAMP2, and corresponding tubulin loading controls, from 14 DIV neurons transduced with scRNA, shRab35, or shRab35 + sh-resistant Rab35 (rRab35) and treated for $24 \mathrm{~h}$ with either DMSO (c) or cycloheximide (chx). E, Quantification of the fold change in degradation of SV2 and VAMP2 for shRab35 versus scRNA control $(n=4) .{ }^{*} p<0.05$. F, Representative immunoblots of SV2, VAMP2, and corresponding tubulin loading control from 14 DIV neurons transduced with scRNA or shRab35 and treated for $24 \mathrm{~h}$ with DMSO (c) or cycloheximide in the presence of additional DMSO or bic/4AP. SV2 and tubulin panels for scRNA condition are also shown in Figure 2F. G, Quantification of fold change in degradation of SV2 and VAMP2 in the presence of scRNA or shRab35, + I- activity. As in Figure 2G, DMSO control is set to 1 for each condition (black bars represent scRNA; red bars represent shRab35), and bic/4AP treatment is expressed as fold change versus DMSO control for that condition $(n=8) .{ }^{*} p<0.05 .{ }^{* *} p<0.01$. $\boldsymbol{H}$, Representative immunoblots of SV2, VAMP2, and corresponding tubulin loading control from 14 DIV neurons transduced with $\mathrm{mCh}$-Rab35 and treated for $24 \mathrm{~h}$ with DMSO (c) or cycloheximide in the presence of additional DMSO or blockers to inhibit neuronal activity. I, Quantification of the fold change in degradation of SV2 and VAMP2 for Rab35 + blockers versus Rab35 DMSO control $(n=3)$. ns, Not significant.

cause the available antibodies against Rab35 and Hrs are not suitable for immunofluorescence microscopy in neurons, we tested this prediction by cotransfecting neurons with mCh-Hrs and either soluble EGFP or EGFP-Rab35. Neurons were subsequently fixed and immunostained for VAMP2, and the percentage colocalization of mCh-Hrs puncta with VAMP2 puncta was quantified and compared in the presence or absence of EGFPRab35. We found that, whereas $\sim 40 \%$ of mCh-Hrs puncta colocalized with VAMP2 at baseline, coexpression of EGFP-Rab35 increased this value to nearly $70 \%$ (Fig. $8 G, I$ ), similar to neuronal activity (Fig. $3 A, C$ ). These data confirm that Rab35 is able to effectively recruit Hrs to SV pools in axons. Similar results were seen with CHMP2B-mCh (Fig. 8 H,I), suggesting that Rab35 recruits Hrs to initiate formation of MVBs in axons.

To better visualize the spatial relationship between Rab35 and ESCRT pathway proteins in axons, we acquired super-resolution images of neurons cotransfected with EGFP-Rab35 and mChHrs or CHMP2B-mCh. EGFP-Rab35 was observed along axons 

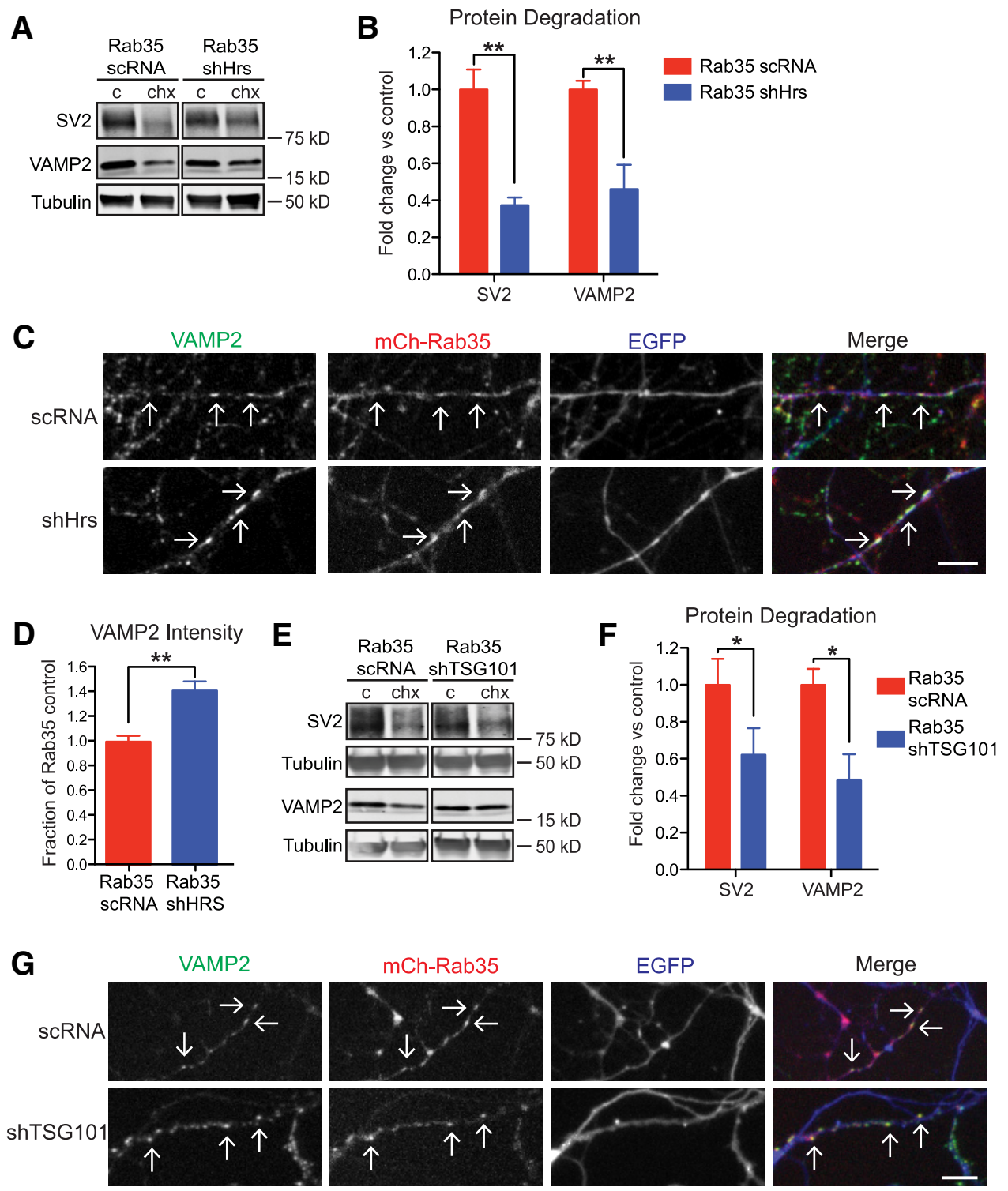

H VAMP2 Intensity

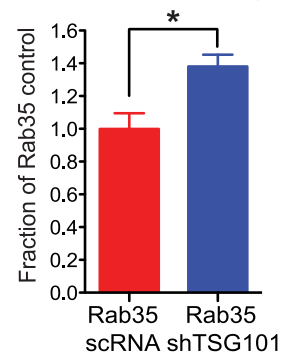

Figure 7. The ESCRT pathway functions downstream of Rab35 to mediate SV protein degradation. $A$, Representative immunoblots of SV2, VAMP2, and corresponding tubulin loading control from 14 DIV neurons transduced with mCh-Rab35 and either scRNA or shHrs, then treated for $24 \mathrm{~h}$ with DMSO (c) or cycloheximide. B, Quantification of the fold change in degradation of SV2 and VAMP2 for Rab35/shHrs versus Rab35/scRNA control $(n=3) .{ }^{* *} p<0.01$. C, Images from 14 DIV neurons transduced with $\mathrm{mCh}$-Rab35 and either scRNA or shHrs (coexpressed with EGFP), fixed $24 \mathrm{~h}$ after cycloheximide treatment, and immunostained against VAMP2. Arrows indicate VAMP2 puncta in axons expressing Rab35 and either scRNA or shHrs. Scale bar, $10 \mu \mathrm{m}$. $\boldsymbol{D}$, Quantification of the average fluorescence intensity of VAMP2 puncta, normalized to Rab35 + scRNA control ( $n=6$ images/condition from 2 replicate weeks, $\sim 100$ puncta/image). ${ }^{* *} p<0.01 . E$, Representative immunoblots of SV2, VAMP2, and corresponding tubulin loading controls from 14 DIV neurons transduced with mCh-Rab35 and either scRNA or shTSG101 (coexpressed with EGFP), treated for $24 \mathrm{~h}$ with DMSO (c) or cycloheximide. $\boldsymbol{F}$, Quantification of the fold change in degradation of SV2 and VAMP2 for Rab35/shTSG versus Rab35/scRNA ( $n=3)$. ${ }^{*} p<0.05$. G, Images from 14 DIV neurons transduced with $\mathrm{mCh}$-Rab35 and either scRNA or shTSG101 (coexpressed with EGFP), fixed $24 \mathrm{~h}$ after cycloheximide treatment and immunostained against VAMP2. Arrows indicate VAMP2 puncta in axons expressing Rab35 and either scRNA or shTSG101. Scale bar, $10 \mu \mathrm{m}$. H, Quantification of the average fluorescence intensity of VAMP2 puncta, normalized to Rab35 + scRNA control ( $n=3$ images/condition, $\sim 100$ puncta/image, similar results obtained for 2 independent experiments). ${ }^{*} p<0.05$. 


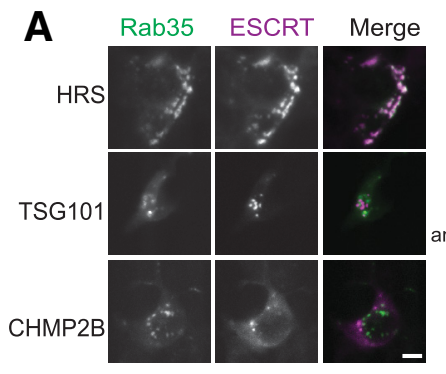

D

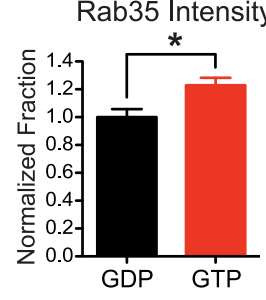

G

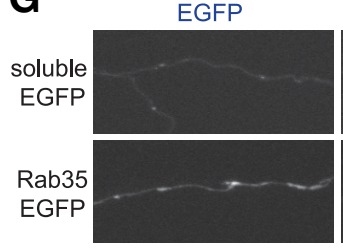

H

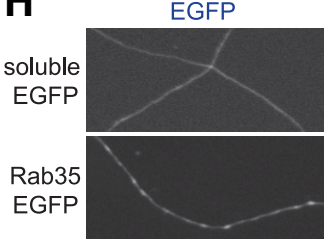

I Colocalization with VAMP2

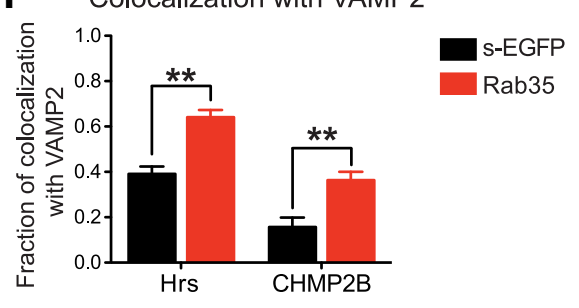

$\mathbf{J}$

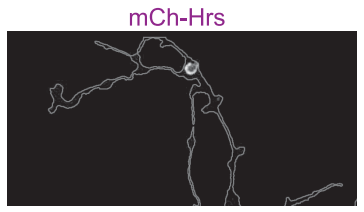

K

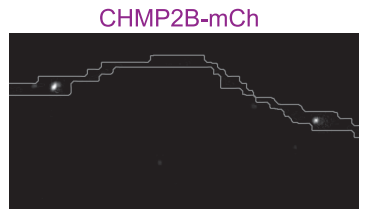

C

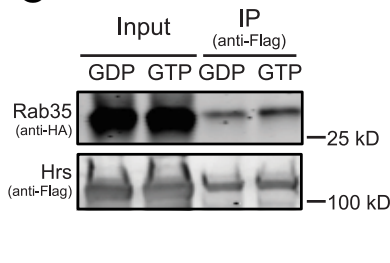

$\mathbf{F}$

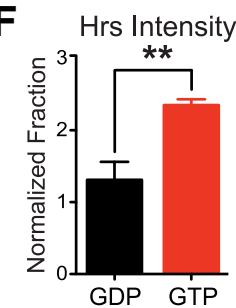

E

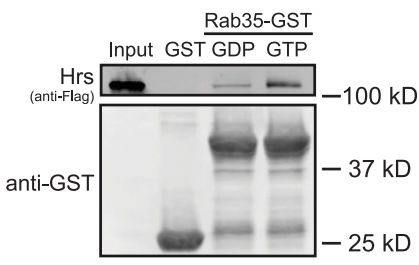

$\mathrm{mCh}-\mathrm{Hrs}$

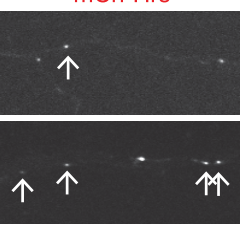

CHMP2B-mCh
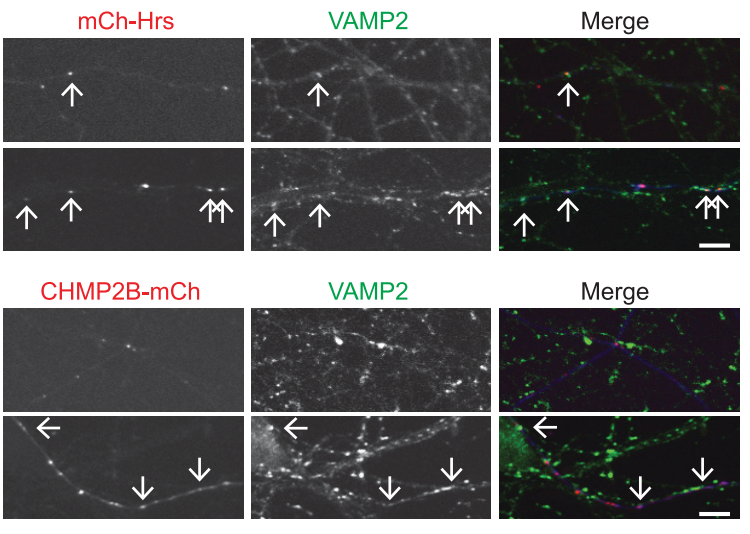

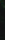

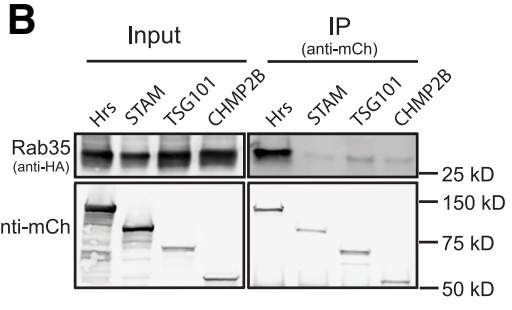
. 
in small puncta and, more rarely, enlarged endosomal structures (Fig. $8 \mathrm{~J}, \mathrm{~K}$ ), on which we focused to resolve the spatial distribution of Rab35 and the ESCRT proteins. EGFP-Rab35 and $\mathrm{mCh}$-Hrs exhibited a high degree of colocalization on these enlarged endosomes (Fig. $8 \mathrm{~J}$ ), indicating that they interact on endosomal membranes. In contrast, CHMP2B-mCh puncta were typically smaller and immediately adjacent Rab35-positive endosomes (Fig. $8 \mathrm{~K}$ ), potentially representing a later stage of MVB formation. Together with our findings in HEK cells, these results indicate that Rab35 colocalizes precisely with the ESCRT-0 component Hrs but much less with later ESCRT pathway components, such as CHMP2B.

\section{Neuronal activity stimulates Rab35 activation}

The ability of Rab35 to initiate ESCRT protein recruitment suggests that neuronal activity serves as a signal to activate Rab35 itself. We tested this hypothesis with an antibody that specifically immunoprecipitates active, GTP-bound Rab35. To verify its specificity, we coexpressed HA-Rab35 in HEK293T cells together with soluble EGFP or EGFPConnecdenn1, a guanine nucleotide exchange factor (GEF) that activates Rab35 (Allaire et al., 2010; Marat and McPherson, 2010). Indeed, Rab35 was more robustly precipitated by the GTP-Rab35 antibody in lysates from cells expressing Connecdenn1 versus soluble EGFP (Fig. 9A). To determine whether Rab35 was activated by neuronal activity, we next compared the levels of GTP-Rab35 in neurons treated with DMSO or bic/4AP. Remarkably, we found that the GTPRab35 antibody precipitated nearly twice as much Rab35 from bic/4AP-treated neurons than from control neurons (Fig. $9 B, C)$, suggesting that increased neuronal activity promotes Rab35 activation/GTP binding. Because Rab35 and Hrs interact in a GTP-dependent manner, neuronal activity should also enhance their binding. To test this, we immunoprecipitated $\mathrm{mCh}-\mathrm{Hrs}$ from neurons treated for $12 \mathrm{~h}$ with bic/4AP. Again, significantly more endogenous Rab35 was coprecipitated with Hrs following treatment with bic/4AP versus DMSO (Fig. $9 D, E)$, indicating that neuronal activity increases the association between Rab35 and Hrs. This activity-dependent association likely catalyzes the recruitment of ESCRT proteins to SV pools, where they can initiate the formation of MVBs for the retrograde transport and lysosomal degradation of specific $\mathrm{SV}$ proteins (Fig. 9F).

\section{Discussion}

Our findings demonstrate that the Rab35/ESCRT pathway mediates the use-dependent degradation of a subset of SV membrane proteins in mammalian neurons. Specifically, we find that neuronal activity induces the activation of Rab35, thereby promoting Hrs binding and recruitment to SV pools. These events in turn recruit the downstream ESCRT machinery, thereby initiating the formation of MVBs for delivery of SV2 and VAMP2 to lysosomes (Fig. 9F). Together, our studies provide novel mechanistic in-

\footnotetext{
$\leftarrow$

(Figure legend continued.) for control, $n=19$ for Rab35 from 3 replicate weeks, each with $\sim 25$ puncta/image; for CHMP2B: $n=5$ for control, $n=8$ for Rab35 from 2 replicate weeks, $\sim 15$ puncta/image). ${ }^{* *} p<0.01$. J, Super-resolution images of neurons cotransfected with EGFP-Rab35 and mCh-Hrs. Inset, Higher-magnification view of Hrs/Rab35 colocalization on an enlarged endosome created by Rab35 overexpression. $\boldsymbol{K}$, Super-resolution images of neurons cotransfected with Rab35 and CHMP2B-mCh. Outline of axons is shown. Inset, Highermagnification view of a Rab35-positive endosome and juxtaposed CHMP2B-mCh puncta. Scale bars: $5 \mu \mathrm{m}$, inset, $2.5 \mu \mathrm{m}$.
}

sight into how neurons maintain SV protein integrity, by degrading proteins that may be damaged or misfolded during SV recycling.

\section{Mechanisms of SV protein turnover}

Mechanisms of SV protein degradation are poorly understood. For instance, the fundamental question of whether SV membrane proteins turn over individually or as a group has not been resolved. In our experiments, we observed variability in the basal turnover rates of SV proteins. Another recent study also found variation in the basal half-lives of SV membrane proteins, ranging from $2.7 \mathrm{~d}$ (Synaptotagmin 1 ) to $5.2 \mathrm{~d}$ (Synaptogyrin 1 ) (Cohen et al., 2013). These findings indicate that SV protein turnover may occur through the regulated degradation of specific proteins as opposed to the degradation of entire SVs. We also observed variability in the dependence of SV-associated protein degradation on neuronal activity, with SV2 and VAMP degradation increased by activity and Synaptotagmin 1 and SNAP-25 degradation unchanged. Why this variability occurs remains an open question. One possibility is that cellular surveillance mechanisms (i.e., molecular chaperones, ubiquitinating enzymes) are coupled to activity to efficiently remove reactive or structurally complex proteins that are susceptible to damage from continuous SV recycling. VAMP2 and SV2 may have structural motifs that are particularly vulnerable to misfolding or oxidation. Alternatively, the specific roles of these proteins (i.e., VAMP2 as the primary v-SNARE in the brain, SV2 as a chaperone for Synaptotagmin1) (Zhang et al., 2015) may depend upon vigilant degradative mechanisms that ensure the maintenance of a highly functional pool of proteins. Interestingly, several groups have shown that specific postsynaptic proteins are ubiquitinated and degraded in an activity-dependent manner, whereas others are not (Ehlers, 2003; Schwarz et al., 2010; Lussier et al., 2011). Moreover, the ubiquitinating enzymes responsible for the ubiquitination/degradation of postsynaptic glutamate receptors are regulated by neuronal activity (Scudder et al., 2014), and such a mechanism could also link activity with SV2 or VAMP2 ubiquitination and degradation.

Another outstanding question is whether SV protein turnover is stochastic, with some constant number of SV proteins being degraded at any given moment, or specific, with particular proteins singled out for degradation based upon their age and/or conformational state. Recent work suggests that older SV proteins are preferentially targeted for degradation (Fernandes et al., 2014; Uytterhoeven et al., 2015), but additional studies are required to understand how the cellular degradative machinery can recognize "old" versus "young" molecules.

\section{Rab GTPases as coordinators of SV protein turnover}

In this study, we found that two Rab GTPases (Rab5 and Rab35) are capable of driving VAMP2 and SV2 degradation. Whereas Rab35 interacts with Hrs and specifically mediates the degradation of SV integral membrane proteins, Rab5 does not interact with Hrs, and stimulates the turnover of multiple presynaptic proteins (plasma membrane and active zone-associated), suggesting that it activates a broader degradative program. One possibility, based on Rab5's link to the autophagic pathway (Ravikumar et al., 2008; Su et al., 2011; Dou et al., 2013), is that its overexpression in neurons activates macroautophagy. Indeed, previous studies have shown that stimulating macroautophagy in neurons can induce the engulfment of SVs, cytoplasmic proteins, and other organelles by autophagosomes (Hernandez et al., 2012; Sanchez-Varo et al., 2012; Maday et al., 2014). Interestingly, a recent study has linked the SV-associated Rab26 to the au- 
A

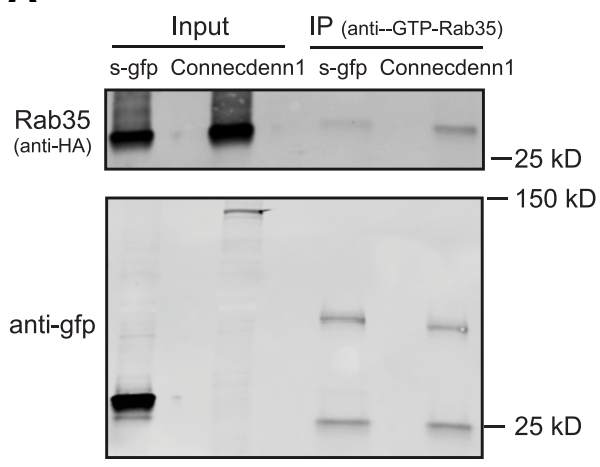

D

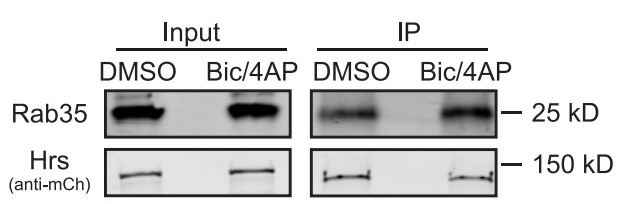

B

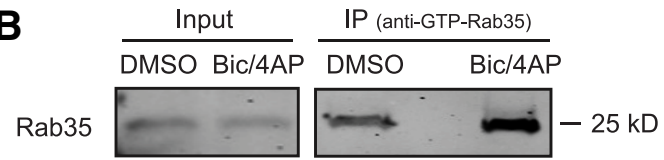

C

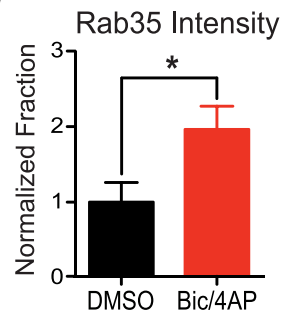

E Rab35 Intensity

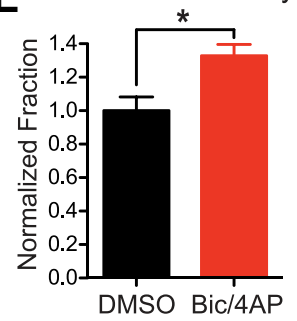

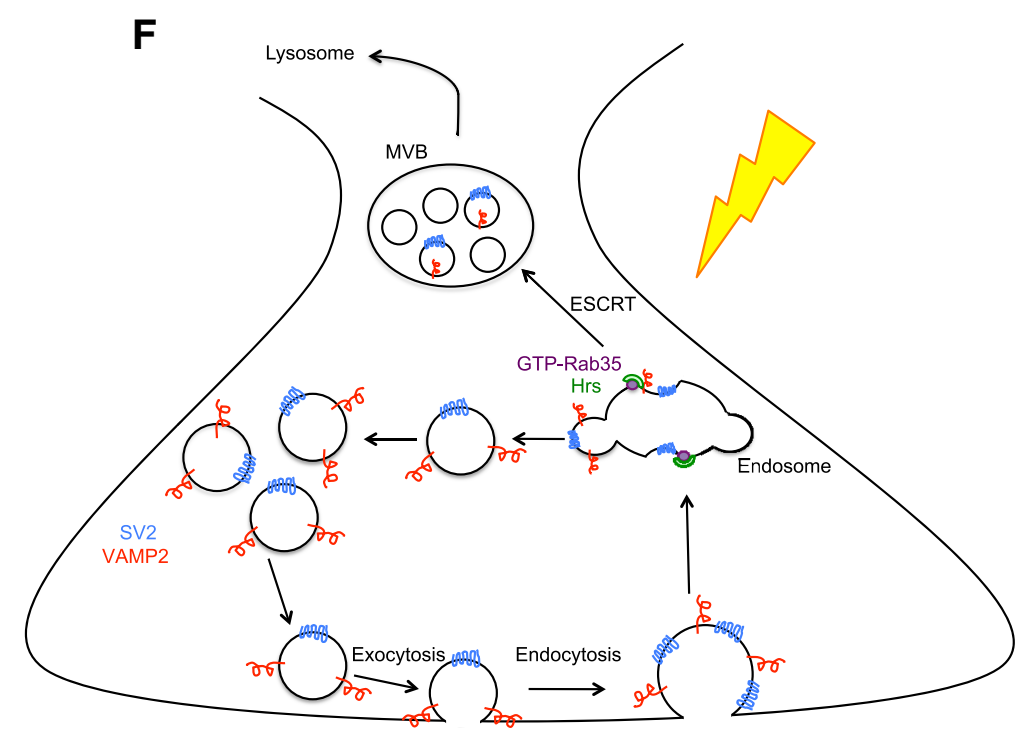

Figure 9. Neuronal activity activates Rab35 and stimulates Rab35-Hrs binding. A, Lysates from HEK293T cells cotransfected with HA-Rab35 and either soluble GFP or Connecdenn1-GFP, subject to IP with GTP-Rab35 specific antibody. Bound proteins and input were probed with GFP and HA antibodies. IgG bands appear on the GFP immunoblot for IP eluates. $\boldsymbol{B}$, Immunoblots from 15 DIV neurons treated with DMSO or bic/4AP for $12 \mathrm{~h}$, then lysed and subject to IP with mouse GTP-Rab35 specific antibody and probed with rabbit Rab35 antibody. C, Quantification of Rab35 intensity in the eluate, normalized to input intensity and reported as a fraction of the DMSO control condition $(n=7) .{ }^{*} p<0.05$. D, Immunoblots from neurons transduced with Hrs-mCh and treated with DMSO or bic/4AP for $12 \mathrm{~h}$, then lysed and subject to IP with anti-mCherry antibody. Bound proteins and input were probed with Rab35 and mCherry antibodies. E, Quantification of Rab35 intensity in the eluate, normalized to input intensity and Hrs intensity in the eluate. Bic/4AP condition is reported as a fraction of the DMSO control condition $(n=3)$. ${ }^{*} p<0.05$. $\boldsymbol{F}$, Putative pathway for activity-dependent SV protein degradation. Neuronal activity (lightning bolt) serves to activate Rab35, which then recruits its effector, Hrs, to presynaptic endosomes. This recruitment is hypothesized to initiate MVB formation, leading to retrograde transport and delivery of specific SV proteins (SV2 and VAMP2) to somatic lysosomes for degradation.

tophagic pathway, showing that Rab26 overexpression induces SV clustering and engulfment by autophagosomes (Binotti et al., 2015). Although our findings indicate that basal and activitydependent SV protein turnover occurs through Rab35 and the ESCRT pathway, it is likely that specific stimuli and developmental programs (e.g., oxidative stress, protein aggregation, synapse elimination/pruning) can activate macroautophagy to degrade SVs and other synaptic components under certain conditions.
Additional studies are needed to investigate the conditions under which the ESCRT pathway and macroautophagy are used for SV protein degradation.

Two other SV-associated Rabs that we evaluated (Rab10 and Rab14) do not alter SV protein degradation but do interact with Hrs. We hypothesize that these Rabs also participate in trafficking in the endolysosomal pathway but target different classes of membrane-associated proteins. Gain- and loss-of-function stud- 
ies combined with proteomics-based approaches are likely to yield insights into the proteins targeted by these Rabs.

\section{Rab35 links SV protein degradation to the ESCRT pathway through its effector Hrs}

Previous studies identified Rab35 as an important regulator of the endosomal sorting and turnover of SV proteins (Uytterhoeven et al., 2011; Fernandes et al., 2014). Here, we provide mechanistic insight into how Rab35 mediates the degradation of SV proteins, by directly linking Rab35 to the ESCRT-0 component Hrs. The GTP-dependent Rab35/Hrs binding interaction implicates the ESCRT pathway as a critical mediator of SV protein degradation downstream of Rab35. Not only is the ESCRT pathway essential for recruiting ubiquitinated membrane proteins destined for degradation, but it also catalyzes the formation of MVBs to deliver this cargo to lysosomes. Previous work has shown that MVBs often appear in EM micrographs of presynaptic boutons following neuronal stimulation (Teichberg et al., 1975), suggestive of activity-dependent formation. This concept is consistent with our data showing that neuronal activity stimulates protein turnover and the recruitment of ESCRT proteins to SV pools. Future studies will assess whether activity stimulates the formation and retrograde transport of MVBs in axons.

\section{Use-dependent turnover of SV proteins}

Not only does this study directly link neuronal activity to SV protein turnover, it is also the first to report that neuronal activity can induce Rab GTPase activation. Although the GAPs and GEFs for many Rabs have been characterized (for review, see Barr and Lambright, 2010), few studies have addressed the signals responsible for Rab activation/inactivation. A recent study found that CnrF, a Rab11 GAP, is activated by calcium release through vacuolar P2XA ion channels, thereby inactivating Rab11 in response to P2XA channel activation (Parkinson et al., 2014). Similarly, neuronal activity may induce activation or inactivation of Rab35 GEFs or GAPs, respectively, thereby stabilizing Rab35 in its GTPbound conformation. Candidate GEFs and GAPs to regulate synaptic Rab35 activation include Connecdenn1, a presynaptically enriched GEF that interacts with clathrin to mediate SV recycling (Allaire et al., 2006), and TBC1D24/skywalker, a GAP shown to negatively regulate Rab35 activity in presynaptic terminals of Drosophila (Uytterhoeven et al., 2011). Whether and how these molecules regulate Rab35 activation in response to synaptic activity or other stimuli is an interesting topic for future studies.

\section{SV protein homeostasis and neurodegeneration}

An inability to maintain SV protein homeostasis is implicated as a causative factor in neurodegenerative diseases. Indeed, the accumulation of damaged or misfolded SV-associated proteins can induce neurodegeneration in animal models and humans (Williamson and Neale, 1998; Rozas et al., 2012; Sharma et al., 2012a, b; Peng et al., 2013; Burgoyne and Morgan, 2015). Moreover, SV loss occurs in mouse models of neurodegenerative diseases, including Alzheimer's, Parkinson's, and lysosomal storage disorder, often before the emergence of other phenotypes (Virmani et al., 2005; Scott et al., 2010; Esposito et al., 2012; Sanchez-Varo et al., 2012). These findings suggest that maintaining functional SV pools is critical for synaptic and neuronal health, and that disruption of SV protein homeostasis mechanisms can trigger broader neurodegenerative processes. Interestingly, loss-offunction mutations in TBC1D24/skywalker and the ESCRT proteins Hrs and CHMP2B cause neurodegeneration in mice and Drosophila as well as in humans (Lee et al., 2007, 2009; Tamai et al., 2008; Guven and Tolun, 2013; Fernandes et al., 2014), implicating this highly conserved pathway in the etiology of neurodegenerative disease. Whereas TBC1D24/skywalker mutations promote Rab35 overactivation and SV protein degradation, ESCRT mutations impair this process, leading to the accumulation of ubiquitinated proteins and degradative structures (Lee et al., 2007, 2009; Tamai et al., 2008; Guven and Tolun, 2013; Fernandes et al., 2014). Additionally, it was recently reported that mice expressing artificially ubiquitinated VAMP2 develop progressive degeneration of nerve terminals with obvious loss of synaptic vesicle density and the accumulation of tubulovesicular structures (Liu et al., 2015). These intriguing findings suggest that both the exuberant, unregulated degradation of proteins and the accumulation of dysfunctional, ubiquitinated proteins are harmful to neurons. Thus, further study of the Rab35/ESCRT pathway will not only provide insight into how SV protein turnover and homeostasis are regulated but will also facilitate the identification of factors that promote or inhibit protein degradation, and could therefore serve as therapeutic targets for the treatment of neurodegenerative disease.

\section{References}

Allaire PD, Ritter B, Thomas S, Burman JL, Denisov AY, Legendre-Guillemin V, Harper SQ, Davidson BL, Gehring K, McPherson PS (2006) Connecdenn, a novel DENN domain-containing protein of neuronal clathrin-coated vesicles functioning in synaptic vesicle endocytosis. J Neurosci 26:13202-13212. CrossRef Medline

Allaire PD, Marat AL, Dall'Armi C, Di Paolo G, McPherson PS, Ritter B (2010) The Connecdenn DENN domain: a GEF for Rab35 mediating cargo-specific exit from early endosomes. Mol Cell 37:370-382. CrossRef Medline

Alvarez-Castelao B, Schuman EM (2015) The regulation of synaptic protein turnover. J Biol Chem 290:28623-28630. CrossRef Medline

Ao X, Zou L, Wu Y (2014) Regulation of autophagy by the Rab GTPase network. Cell death and differentiation. Cell Death Differ 21:348-358. CrossRef Medline

Babbey CM, Ahktar N, Wang E, Chen CC, Grant BD, Dunn KW (2006) Rab10 regulates membrane transport through early endosomes of polarized Madin-Darby canine kidney cells. Mol Biol Cell 17:3156-3175. CrossRef Medline

Banker G, Goslin K (1998) Culturing nerve cells, Ed 2. Cambridge, MA: Massachusetts Institute of Technology.

Barr F, Lambright DG (2010) Rab GEFs and GAPs. Curr Opin Cell Biol 22:461-470. CrossRef Medline

Bezprozvanny I, Hiesinger PR (2013) The synaptic maintenance problem: membrane recycling, $\mathrm{Ca}^{2+}$ homeostasis and late onset degeneration. Mol Neurodegener 8:23. CrossRef Medline

Binotti B, Pavlos NJ, Riedel D, Wenzel D, Vorbrüggen G, Schalk AM, Kühnel K, Boyken J, Erck C, Martens H, Chua JJ, Jahn R (2015) The GTPase Rab26 links synaptic vesicles to the autophagy pathway. eLife 4:e05597. CrossRef Medline

Bodor DL, Rodríguez MG, Moreno N, Jansen LE (2012) Analysis of protein turnover by quantitative SNAP-based pulse-chase imaging. Curr Protoc Cell Biol 8:8. CrossRef Medline

Brondyk WH, McKiernan CJ, Burstein ES, Macara IG (1993) Mutants of Rab3A analogous to oncogenic Ras mutants: sensitivity to Rab3A-GTPase activating protein and Rab3A-guanine nucleotide releasing factor. J Biol Chem 268:9410-9415. Medline

Brymora A, Valova VA, Robinson PJ (2004) Protein-protein interactions identified by pull-down experiments and mass spectrometry. Curr Protoc Cell Biol 17:15. CrossRef Medline

Burgoyne RD, Morgan A (2015) Cysteine string protein (CSP) and its role in preventing neurodegeneration. Semin Cell Dev Biol 40:153-159. CrossRef Medline

Ceccarelli B, Hurlbut WP, Mauro A (1973) Turnover of transmitter and synaptic vesicles at the frog neuromuscular junction. J Cell Biol 57: 499-524. CrossRef Medline

Cohen LD, Zuchman R, Sorokina O, Müller A, Dieterich DC, Armstrong JD, Ziv T, Ziv NE (2013) Metabolic turnover of synaptic proteins: kinetics, 
interdependencies and implications for synaptic maintenance. PLoS One 8:e63191. CrossRef Medline

Dou Z, Pan JA, Dbouk HA, Ballou LM, DeLeon JL, Fan Y, Chen JS, Liang Z, Li G, Backer JM, Lin RZ, Zong WX (2013) Class IA PI3K p110beta subunit promotes autophagy through Rab5 small GTPase in response to growth factor limitation. Mol Cell 50:29-42. CrossRef Medline

Ehlers MD (2003) Activity level controls postsynaptic composition and signaling via the ubiquitin-proteasome system. Nat Neurosci 6:231-242. CrossRef Medline

Esposito G, Ana Clara F, Verstreken P (2012) Synaptic vesicle trafficking and Parkinson's disease. Dev Neurobiol 72:134-144. CrossRef Medline

Fernandes AC, Uytterhoeven V, Kuenen S, Wang YC, Slabbaert JR, Swerts J, Kasprowicz J, Aerts S, Verstreken P (2014) Reduced synaptic vesicle protein degradation at lysosomes curbs TBC1D24/sky-induced neurodegeneration. J Cell Biol 207:453-462. CrossRef Medline

Fischer von Mollard G, Stahl B, Walch-Solimena C, Takei K, Daniels L, Khoklatchev A, De Camilli P, Südhof TC, Jahn R (1994) Localization of Rab5 to synaptic vesicles identifies endosomal intermediate in synaptic vesicle recycling pathway. Eur J Cell Biol 65:319-326. Medline

Garden GA, La Spada AR (2008) Molecular pathogenesis and cellular pathology of spinocerebellar ataxia type 7 neurodegeneration. Cerebellum 7:138-149. CrossRef Medline

Guven A, Tolun A (2013) TBC1D24 truncating mutation resulting in severe neurodegeneration. J Med Genet 50:199-202. CrossRef Medline

Hernandez D, Torres CA, Setlik W, Cebrián C, Mosharov EV, Tang G, Cheng HC, Kholodilov N, Yarygina O, Burke RE, Gershon M, Sulzer D (2012) Regulation of presynaptic neurotransmission by macroautophagy. Neuron 74:277-284. CrossRef Medline

Hoopmann P, Punge A, Barysch SV, Westphal V, Bückers J, Opazo F, Bethani I, Lauterbach MA, Hell SW, Rizzoli SO (2010) Endosomal sorting of readily releasable synaptic vesicles. Proc Natl Acad Sci U S A 107:1905519060. CrossRef Medline

Junutula JR, De Maziére AM, Peden AA, Ervin KE, Advani RJ, van Dijk SM, Klumperman J, Scheller RH (2004) Rab14 is involved in membrane trafficking between the Golgi complex and endosomes. Mol Biol Cell 15:2218-2229. CrossRef Medline

Komada M, Soriano P (1999) Hrs, a FYVE finger protein localized to early endosomes, is implicated in vesicular traffic and required for ventral folding morphogenesis. Genes Dev 13:1475-1485. CrossRef Medline

Langemeyer L, Nunes Bastos R, Cai Y, Itzen A, Reinisch KM, Barr FA (2014) Diversity and plasticity in Rab GTPase nucleotide release mechanism has consequences for Rab activation and inactivation. eLife 3:e01623. CrossRef Medline

LaVail MM, LaVail JH (1975) Retrograde intraaxonal transport of horseradish peroxidase in retinal ganglion cells of the chick. Brain Res 85: 273-280. CrossRef Medline

Lazarevic V, Schöne C, Heine M, Gundelfinger ED, Fejtova A (2011) Extensive remodeling of the presynaptic cytomatrix upon homeostatic adaptation to network activity silencing. J Neurosci 31:10189-10200. CrossRef Medline

Leal-Ortiz S, Waites CL, Terry-Lorenzo R, Zamorano P, Gundelfinger ED, Garner CC (2008) Piccolo modulation of Synapsinla dynamics regulates synaptic vesicle exocytosis. J Cell Biol 181:831-846. CrossRef Medline

Lee JA, Beigneux A, Ahmad ST, Young SG, Gao FB (2007) ESCRT-III dysfunction causes autophagosome accumulation and neurodegeneration. Curr Biol 17:1561-1567. CrossRef Medline

Lee JA, Liu L, Gao FB (2009) Autophagy defects contribute to neurodegeneration induced by dysfunctional ESCRT-III. Autophagy 5:1070-1072. CrossRef Medline

Li G, Stahl PD (1993) Structure-function relationship of the small GTPase rab5. J Biol Chem 268:24475-24480. Medline

Liu Y, Li H, Sugiura Y, Han W, Gallardo G, Khvotchev M, Zhang Y, Kavalali ET, Südhof TC, Lin W (2015) Ubiquitin-synaptobrevin fusion protein causes degeneration of presynaptic motor terminals in mice. J Neurosci 35:11514-11531. CrossRef Medline

Lois C, Hong EJ, Pease S, Brown EJ, Baltimore D (2002) Germline transmission and tissue-specific expression of transgenes delivered by lentiviral vectors. Science 295:868-872. CrossRef Medline

Lussier MP, Nasu-Nishimura Y, Roche KW (2011) Activity-dependent ubiquitination of the AMPA receptor subunit GluA2. J Neurosci 31: 3077-3081. CrossRef Medline
Maday S, Twelvetrees AE, Moughamian AJ, Holzbaur EL (2014) Axonal transport: cargo-specific mechanisms of motility and regulation. Neuron 84:292-309. CrossRef Medline

Mahoney TR, Liu Q, Itoh T, Luo S, Hadwiger G, Vincent R, Wang ZW, Fukuda M, Nonet ML (2006) Regulation of synaptic transmission by RAB-3 and RAB-27 in Caenorhabditis elegans. Mol Biol Cell 17:26172625. CrossRef Medline

Marat AL, McPherson PS (2010) The connecdenn family, Rab35 guanine nucleotide exchange factors interfacing with the clathrin machinery. J Biol Chem 285:10627-10637. CrossRef Medline

McCaffrey MW, Bielli A, Cantalupo G, Mora S, Roberti V, Santillo M, Drummond F, Bucci C (2001) Rab4 affects both recycling and degradative endosomal trafficking. FEBS Lett 495:21-30. CrossRef Medline

Parkinson K, Baines AE, Keller T, Gruenheit N, Bragg L, North RA, Thompson CR (2014) Calcium-dependent regulation of Rab activation and vesicle fusion by an intracellular P2X ion channel. Nat Cell Biol 16:87-98. CrossRef Medline

Pavlos NJ, Jahn R (2011) Distinct yet overlapping roles of Rab GTPases on synaptic vesicles. Small GTPases 2:77-81. CrossRef Medline

Pavlos NJ, Grønborg M, Riedel D, Chua JJ, Boyken J, Kloepper TH, Urlaub H, Rizzoli SO, Jahn R (2010) Quantitative analysis of synaptic vesicle Rabs uncovers distinct yet overlapping roles for Rab3a and Rab27b in $\mathrm{Ca}^{2+}$. triggered exocytosis. J Neurosci 30:13441-13453. CrossRef Medline

Peng L, Liu H, Ruan H, Tepp WH, Stoothoff WH, Brown RH, Johnson EA, Yao WD, Zhang SC, Dong M (2013) Cytotoxicity of botulinum neurotoxins reveals a direct role of syntaxin 1 and SNAP-25 in neuron survival. Nat Commun 4:1472. CrossRef Medline

Raiborg C, Stenmark H (2009) The ESCRT machinery in endosomal sorting of ubiquitylated membrane proteins. Nature 458:445-452. CrossRef Medline

Ravikumar B, Imarisio S, Sarkar S, O'Kane CJ, Rubinsztein DC (2008) Rab5 modulates aggregation and toxicity of mutant huntingtin through macroautophagy in cell and fly models of Huntington disease. J Cell Sci 121: 1649-1660. CrossRef Medline

Rizzoli SO, Bethani I, Zwilling D, Wenzel D, Siddiqui TJ, Brandhorst D, Jahn R (2006) Evidence for early endosome-like fusion of recently endocytosed synaptic vesicles. Traffic 7:1163-1176. CrossRef Medline

Rozas JL, Gómez-Sánchez L, Mircheski J, Linares-Clemente P, NietoGonzález JL, Vázquez ME, Luján R, Fernández-Chacón R (2012) Motorneurons require cysteine string protein-alpha to maintain the readily releasable vesicular pool and synaptic vesicle recycling. Neuron 74: 151-165. CrossRef Medline

Sanchez-Varo R, Trujillo-Estrada L, Sanchez-Mejias E, Torres M, BagliettoVargas D, Moreno-Gonzalez I, De Castro V, Jimenez S, Ruano D, Vizuete M, Davila JC, Garcia-Verdugo JM, Jimenez AJ, Vitorica J, Gutierrez A (2012) Abnormal accumulation of autophagic vesicles correlates with axonal and synaptic pathology in young Alzheimer's mice hippocampus. Acta Neuropathol 123:53-70. CrossRef Medline

Sato M, Sato K, Liou W, Pant S, Harada A, Grant BD (2008) Regulation of endocytic recycling by $C$. elegans Rab35 and its regulator RME-4, a coated-pit protein. EMBO J 27:1183-1196. CrossRef Medline

Schlüter OM, Schnell E, Verhage M, Tzonopoulos T, Nicoll RA, Janz R, Malenka RC, Geppert M, Südhof TC (1999) Rabphilin knock-out mice reveal that rabphilin is not required for rab3 function in regulating neurotransmitter release. J Neurosci 19:5834-5846. Medline

Schlüter OM, Schmitz F, Jahn R, Rosenmund C, Südhof TC (2004) A complete genetic analysis of neuronal Rab3 function. J Neurosci 24:66296637. CrossRef Medline

Schmidt O, Teis D (2012) The ESCRT machinery. Curr Biol 22:R116-R120. CrossRef Medline

Schwarz LA, Hall BJ, Patrick GN (2010) Activity-dependent ubiquitination of GluA1 mediates a distinct AMPA receptor endocytosis and sorting pathway. J Neurosci 30:16718-16729. CrossRef Medline

Scott DA, Tabarean I, Tang Y, Cartier A, Masliah E, Roy S (2010) A pathologic cascade leading to synaptic dysfunction in alpha-synuclein-induced neurodegeneration. J Neurosci 30:8083-8095. CrossRef Medline

Scudder SL, Goo MS, Cartier AE, Molteni A, Schwarz LA, Wright R, Patrick GN (2014) Synaptic strength is bidirectionally controlled by opposing activity-dependent regulation of Nedd4-1 and USP8. J Neurosci 34: 16637-16649. CrossRef Medline

Sharma M, Burré J, Südhof TC (2011) CSPalpha promotes SNARE- 
complex assembly by chaperoning SNAP-25 during synaptic activity. Nat Cell Biol 13:30-39. CrossRef Medline

Sharma M, Burré J, Bronk P, Zhang Y, Xu W, Südhof TC (2012a) CSPalpha knockout causes neurodegeneration by impairing SNAP-25 function. EMBO J 31:829-841. CrossRef Medline

Sharma M, Burré J, Südhof TC (2012b) Proteasome inhibition alleviates SNARE-dependent neurodegeneration. Sci Transl Med 4:147ral13. CrossRef Medline

Shimizu H, Kawamura S, Ozaki K (2003) An essential role of Rab5 in uniformity of synaptic vesicle size. J Cell Sci 116:3583-3590. CrossRef Medline

Star EN, Newton AJ, Murthy VN (2005) Real-time imaging of Rab3a and Rab5a reveals differential roles in presynaptic function. J Physiol 569: 103-117. CrossRef Medline

Stenmark H (2009) Rab GTPases as coordinators of vesicle traffic. Nat Rev Mol Cell Biol 10:513-525. CrossRef Medline

Su WC, Chao TC, Huang YL, Weng SC, Jeng KS, Lai MM (2011) Rab5 and class III phosphoinositide 3-kinase Vps34 are involved in hepatitis C virus NS4B-induced autophagy. J Virol 85:10561-10571. CrossRef Medline

Takamori S, Holt M, Stenius K, Lemke EA, Grønborg M, Riedel D, Urlaub H, Schenck S, Brügger B, Ringler P, Müller SA, Rammner B, Gräter F, Hub JS, De Groot BL, Mieskes G, Moriyama Y, Klingauf J, Grubmuller H, Heuser J, et al. (2006) Molecular anatomy of a trafficking organelle. Cell 127:831-846. CrossRef Medline

Tamai K, Toyoshima M, Tanaka N, Yamamoto N, Owada Y, Kiyonari H, Murata K, Ueno Y, Ono M, Shimosegawa T, Yaegashi N, Watanabe M, Sugamura K (2008) Loss of hrs in the central nervous system causes accumulation of ubiquitinated proteins and neurodegeneration. J Pathol 173:1806-1817. CrossRef Medline

Tauskela JS, Fang H, Hewitt M, Brunette E, Ahuja T, Thivierge JP, Comas T, Mealing GA (2008) Elevated synaptic activity preconditions neurons against an in vitro model of ischemia. J Biol Chem 283:34667-34676. CrossRef Medline

Teichberg S, Holtzman E, Crain SM, Peterson ER (1975) Circulation and turnover of synaptic vesicle membrane in cultured fetal mammalian spinal cord neurons. J Cell Biol 67:215-230. CrossRef Medline

Uytterhoeven V, Kuenen S, Kasprowicz J, Miskiewicz K, Verstreken P (2011)
Loss of skywalker reveals synaptic endosomes as sorting stations for synaptic vesicle proteins. Cell 145:117-132. CrossRef Medline

Uytterhoeven V, Lauwers E, Maes I, Miskiewicz K, Melo MN, Swerts J, Kuenen S, Wittocx R, Corthout N, Marrink SJ, Munck S, Verstreken P (2015) Hsc70 - 4 deforms membranes to promote synaptic protein turnover by endosomal microautophagy. Neuron 88:735-748. CrossRef Medline

Virmani T, Gupta P, Liu X, Kavalali ET, Hofmann SL (2005) Progressively reduced synaptic vesicle pool size in cultured neurons derived from neuronal ceroid lipofuscinosis-1 knockout mice. Neurobiol Dis 20:314-323. CrossRef Medline

Waites CL, Specht CG, Härtel K, Leal-Ortiz S, Genoux D, Li D, Drisdel RC, Jeyifous O, Cheyne JE, Green WN, Montgomery JM, Garner CC (2009) Synaptic SAP97 isoforms regulate AMPA receptor dynamics and access to presynaptic glutamate. J Neurosci 29:4332-4345. CrossRef Medline

Waites CL, Leal-Ortiz SA, Andlauer TF, Sigrist SJ, Garner CC (2011) Piccolo regulates the dynamic assembly of presynaptic F-actin. J Neurosci 31: 14250-14263. CrossRef Medline

Wang D, Chan CC, Cherry S, Hiesinger PR (2013) Membrane trafficking in neuronal maintenance and degeneration. Cell Mol Life Sci 70:2919-2934. CrossRef Medline

Wijayatunge R, Chen LF, Cha YM, Zannas AS, Frank CL, West AE (2014) The histone lysine demethylase $\mathrm{Kdm} 6 \mathrm{~b}$ is required for activity-dependent preconditioning of hippocampal neuronal survival. Mol Cell Neurosci 61:187-200. CrossRef Medline

Williamson LC, Neale EA (1998) Syntaxin and 25-kDa synaptosomalassociated protein: differential effects of botulinum neurotoxins $\mathrm{C} 1$ and $\mathrm{A}$ on neuronal survival. J Neurosci Res 52:569-583. CrossRef Medline

Wucherpfennig T, Wilsch-Bräuninger M, González-Gaitán M (2003) Role of Drosophila Rab5 during endosomal trafficking at the synapse and evoked neurotransmitter release. J Cell Biol 161:609-624. CrossRef Medline

Yu E, Kanno E, Choi S, Sugimori M, Moreira JE, Llinás RR, Fukuda M (2008) Role of Rab27 in synaptic transmission at the squid giant synapse. Proc Natl Acad Sci U S A 105:16003-16008. CrossRef Medline

Zhang N, Gordon SL, Fritsch MJ, Esoof N, Campbell DG, Gourlay R, Velupillai S, Macartney T, Peggie M, van Aalten DM, Cousin MA, Alessi DR (2015) Phosphorylation of synaptic vesicle protein $2 \mathrm{~A}$ at Thr84 by casein kinase 1 family kinases controls the specific retrieval of synaptotagmin-1. J Neurosci 35:2492-2507. CrossRef Medline 